Formatted: Font color: Custom Color(RGB $(46 ; 116 ; 181))$

Formatted: Left: $25 \mathrm{~mm}$, Right: $25 \mathrm{~mm}$, Top: $25 \mathrm{~mm}$, Bottom: 25 mm, Width: $210 \mathrm{~mm}$, Height: 297 $\mathrm{mm}$, Header distance from edge: $12.5 \mathrm{~mm}$, Footer distance from edge: $12.5 \mathrm{~mm}$, Different first page header

Formatted: Font color: Custom Color(RGB(46;116;181))

Formatted: Font: (Default) Calibri, 11 pt, Not Bold

Formatted: Normal, After: $0 \mathrm{~mm}$, Space Before: 0 pt, After: 0 pt

\section{.. rmatted}

rmatted

Formatted: Complex Script Font: Bold

Formatted: Font: $18 \mathrm{pt}$

Formatted: Centered

Formatted: Superscript

Formatted: Centered

Formatted: Superscript

rmatted

Formatted: Font: Not Italic

rmatted

Formatted: Font: Not Italic

Formatted: Indent: Before: $0 \mathrm{~mm}$

rmatted

Formatted: Font: $12 \mathrm{pt}$

Formatted: Space Before: 0 pt, After: 0 pt, Line spacing: Exactly $12 \mathrm{pt}$

Formatted: Font: 12 pt, English (United States)

Formatted: Font: $12 \mathrm{pt}$

Formatted: Space After: 0 pt, Line spacing: Exactly $12 \mathrm{pt}$

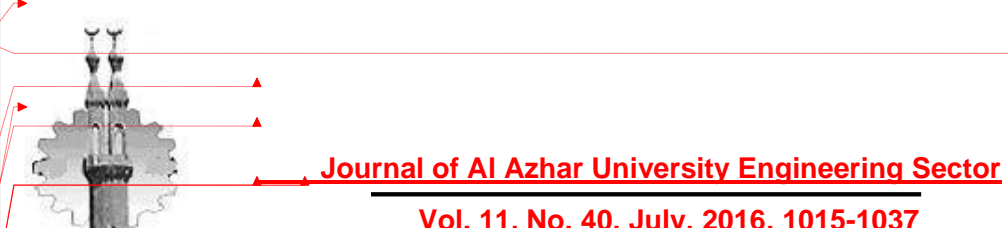

JAUES

Vol. 11, No. 40, July, 2016, 1015-1037

\title{
A MICROSIMULATION APPROACH TO EVALUATE OPERAT OF WEAVING SECTIONS AT URBAN UNCONVENTIONA] INTERSECTIONS IN CAIRO
}

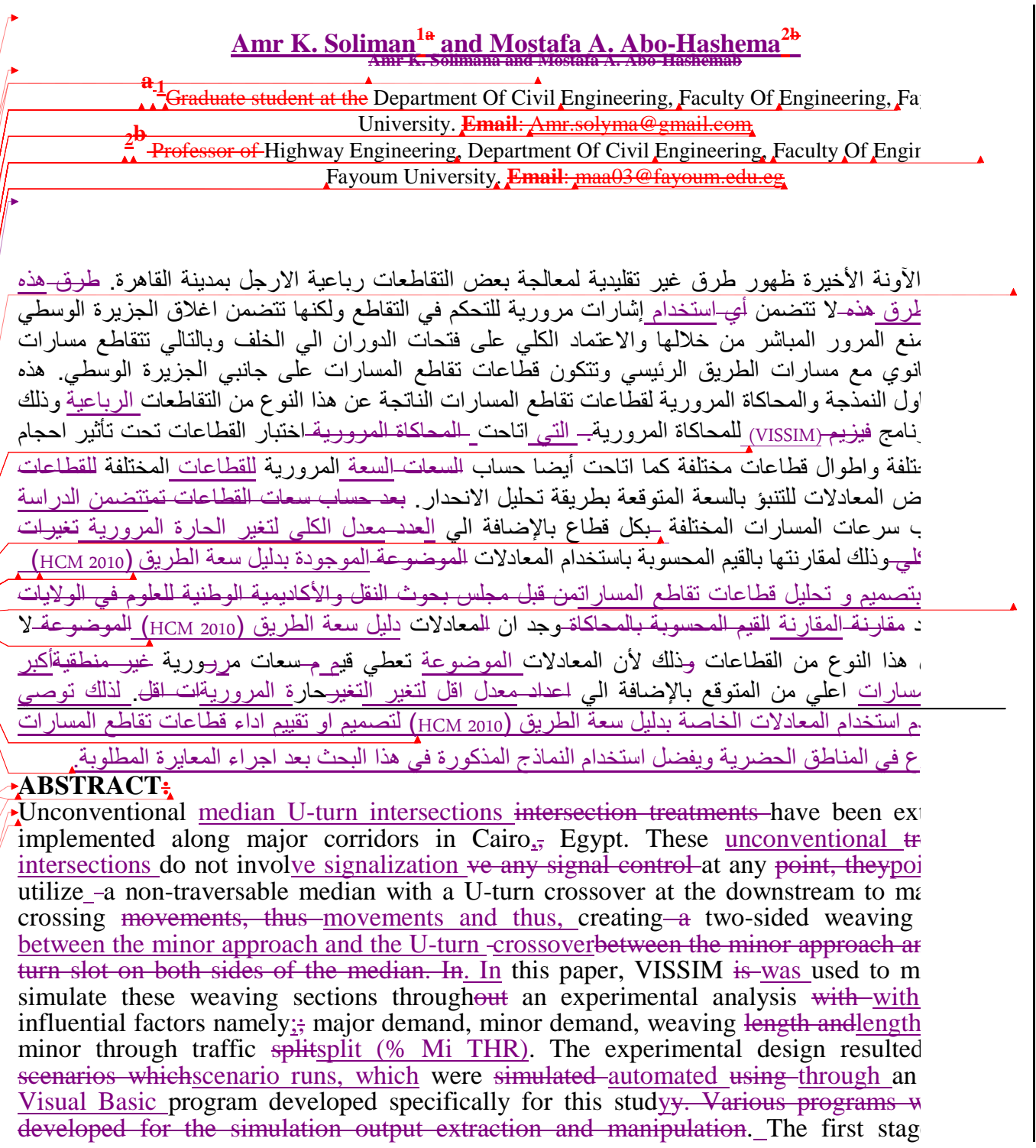


Formatted: Font: 8 pt, Not Bold

Formatted: Font: 8 pt, Not Bold
Formatted: Font: $12 \mathrm{pt}$, Bold

Formatted: Font: $12 \mathrm{pt}$, Bold

Formatted: Space Before: $0 \mathrm{pt}$, After: $0 \mathrm{pt}$, No bullets or numbering

Formatted: Font: Not Bold

Formatted: Font: $12 \mathrm{pt}$

Formatted: Font: $12 \mathrm{pt}$

Formatted: Font: $12 \mathrm{pt}$, Font color: Red

Formatted: Font: 12 pt, Font color: Red

Formatted: Font: 12 pt, Font color: Red

Formatted: Font: 12 pt, Font color: Red

Formatted: Font: $12 \mathrm{pt}$, Font color: Red

Formatted: Tab stops: Not at 82.5 $\mathrm{mm}+165.1 \mathrm{~mm}$
A MICROSIMULATION APPROACH TO EVALUATE OPERATIONS OF WEAVING SECTIONS AT URBAN UNCONV INTERSECTIONS IN CAIRO

Soliman, A.K. and Abo Hashema, M.A.Soliman, A.K. and Abo Hashema, M.A.

4

analysis was dedicatedwas dedicated to estimate the capacities of to estimate the capi the weaving sections and the minor entrance whichentrance, which were found $t$ t negatively eorrelation-correlated. with each other.Increasing the major demand , decrease in the minor entrance capacity and an increase in the capacities of the Itsections. It -was also found that increasing capacities increase with the increc weaving length-; however, increasing the length beyond 200 meters was not $b$ r Increasing the minor through split caused an increase in volume ratio and a dec capacities-Furthermore. Furthermore, regression analysis was used to develop; simulation based capacity prediction models that resulted in a relatively high $\mathrm{R}^{2}$ val second stage of the analysis eovered-was dedicated to thetest the application-approp of the HCM 2010 weaving methodology to-when applied to the urban weaving se predict capacities, lane change rates, and speedscompute capacities, lane chan weaving and non weaving speeds for each weaving section. Comparisons betv predicted and the simulated estimates with the simulation models sshowed that $F$ HCM 2010 2010-methodology provides-provided higher extremely highcapacity pr up to 1.6 times the capacity estimates almost double the simulated eapacitiescapaciti HCM 2010 also provided lower capacities for higher weaving lengths, which int higher sensitivity to the increase in volume ratio and a lower sensitivity to the int weaving length-. On the other hand, Thethe developed regression models on the ot provided-produced capacity more accurate estimationsestimations that were more This provided evidence that the structure of the developed models represent capacities of similar weaving configurations. Further comparisons using tests and parity plots between the simulated and the predicted estimates showed tha 2010the HCM 2010 methodology also underpredicted the-lane change rates in the sectionrates; s and thereby-therefore, producing higher-speed predictions were higher simulated speeds -estimatesat each weaving section. FinallyFinally, an effor undertaken carried out to calibrate and modify the speed prediction algorithms of $t$ 2010-2010speed prediction algorithms using the simulation data points; did not produce-yield any significant results.

Keywords: VISSIM, Microscopic traffic simulation, Urban-weavingUrbansections, HCM 2010, Capacity analysis, Unconventional intersection treatments

\section{INTRODUCTION}

Most of the weaving related research is focused on freeway weaving section $\mathrm{du}$ complexity of analyzing operations with interruptions to the flow. In urban, envir disturbances to the traffic flow could be causes by various elements such as cre access, driveways, traffic signals, yield control, stop signs, pedestrians, on street parki

Despite, being the state of the art transportation document, the HCM 2010 also-stops addressing weaving in urban areas with interrupted flow conditions. It prf methodology limited to freeway conditions. Practitioners use the HCM 2010 method design and analyze alternative weaving sections. However, using it to address urban is controversial.

To date, there has not been a recognized procedure for the analysis of urban weaving however, simulation seems to be a reliable and sophisticated analysis approack extensively used nowadays to address limitation of available methodologies and complex traffic phenomenon. VISSIM traffic simulater is a very sophisticated timebehavioral based simulation model developed to model urban traffic, and public tra: addition to pedestrian's flows. VISSIM offers flexibility in several respects. The sf programmability overcomes the limitation of the graphical interface. Also the concep 


\begin{tabular}{|c|}
\hline ... rmatted \\
\hline ... rmatted \\
\hline ... rmatted \\
\hline ... rmatted \\
\hline ... rmatted \\
\hline ... rmatted \\
\hline ... rmatted \\
\hline ... rmatted \\
\hline ... Id Code Changed \\
\hline ... rmatted \\
\hline ... rmatted \\
\hline ... rmatted \\
\hline ... rmatted \\
\hline ... rmatted \\
\hline ... rmatted \\
\hline ... rmatted \\
\hline ... rmatted \\
\hline ... rmatted \\
\hline ... rmatted \\
\hline ... rmatted \\
\hline ... rmatted \\
\hline ... rmatted \\
\hline ... rmatted \\
\hline ... rmatted \\
\hline ... rmatted \\
\hline ... rmatted \\
\hline ... rmatted \\
\hline ... rmatted \\
\hline ... rmatted \\
\hline ... rmatted \\
\hline ... rmatted \\
\hline ... rmatted \\
\hline ... rmatted \\
\hline ... rmatted \\
\hline ... rmatted \\
\hline ... rmatted \\
\hline ... rmatted \\
\hline ... rmatted \\
\hline ... rmatted \\
\hline
\end{tabular}

A MICROSIMULATION APPROACH TO EVALUATE OPERATIONS OF WEAVING SECTIONS AT URBAN UNCONV INTERSECTIONS IN CAIRO

Soliman, A.K. and Abo Hashema, M.A.Soliman, A.K. and Abo Hashema, M.A.

4

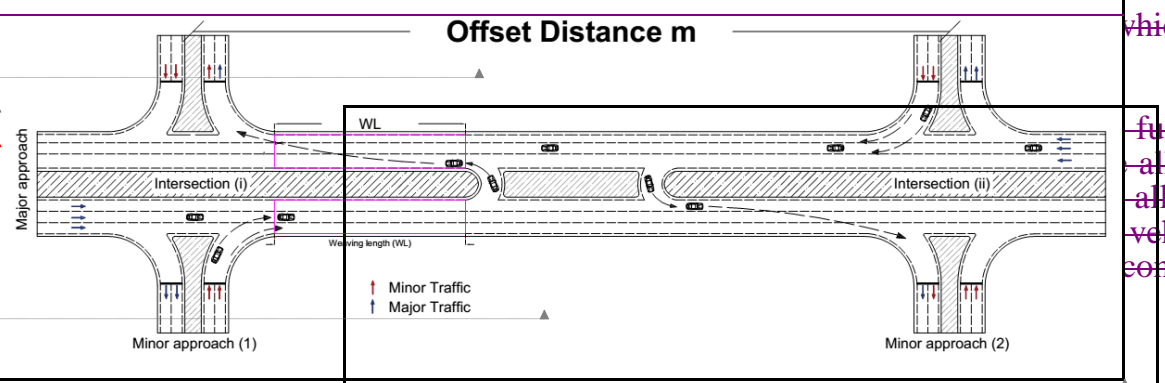

Figure 1: Typical Intersection Treatment in Cairo,

As consequence of implementing this unconventional intersection treatment, di turning (DLT) vehicles of minor street are forced to make a right turn followed byi (RTUT). On the other ha then at right turn (RT) int street must also utilize (UTRT) inte the miner a

The RTUT movement re the Uturn crossover, thu main traffic stream. Sim toward the miner appre flow, as well.

Figure 2 illustrates the intersection treatment.

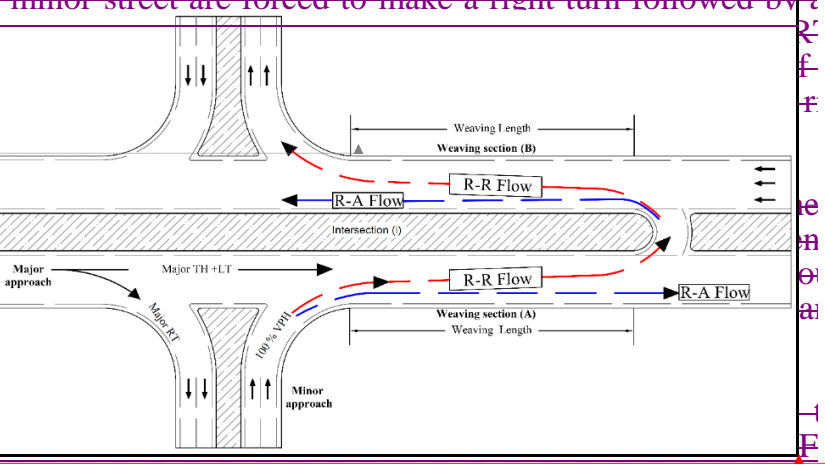

Flow components and the formation of weaving sections

The HCM 2010 [1] defines weaving as the crossing of two or more traffic streams wi aid of traffic control devices along a significant length of highway. Traffic passing the weaving section experience turbulence in excess of the normally present on roadway. This additional turbulence causes a reduction in capacity and performance.

In Cairo, many urban intersections have been treated with U-turns as shown in figure the full median opening is substituted with a crossover, downstream of the inters handle all crossing movements. This treatment does not involve any signals contrc point. Conflicts between traffic streams are managed through yield signs, therefore, vehicles are forced to yield to the mainstream traffic at all times.

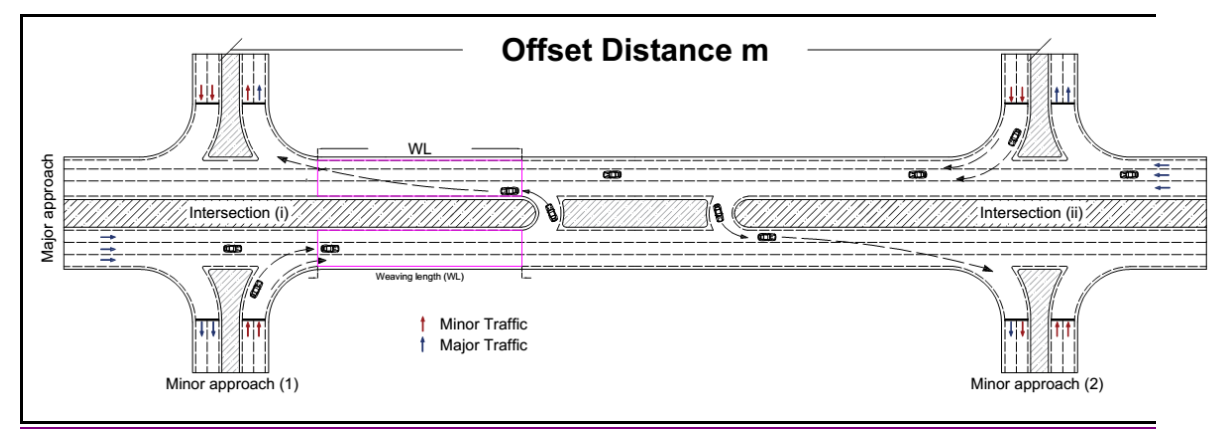

Figure.,111: Typical unconventional intersection design at an urban corridor in Cairo 


\section{Formatted: Font: 8 pt, Not Bold \\ Formatted: Font: 8 pt, Not Bold}

Formatted: Font: 12 pt, Not Bold

\begin{tabular}{|c|}
\hline Formatted: Font: $12 \mathrm{pt}$ \\
\hline Formatted: Font: $12 \mathrm{pt}$, Not Bold \\
\hline Formatted: Font: $12 \mathrm{pt}$ \\
\hline $\begin{array}{l}\text { Formatted: Centered, After: } 0.5 \\
\mathrm{~mm}\end{array}$ \\
\hline $\begin{array}{l}\text { Formatted: Font: Times New } \\
\text { Roman, } 10 \text { pt, Font color: Black }\end{array}$ \\
\hline $\begin{array}{l}\text { Formatted: Centered, Space } \\
\text { Before: } 0 \text { pt, After: } 0 \text { pt }\end{array}$ \\
\hline Formatted: Font color: Black \\
\hline $\begin{array}{l}\text { Formatted: Font: Times New } \\
\text { Roman, } 10 \text { pt, Font color: Black }\end{array}$ \\
\hline $\begin{array}{l}\text { Formatted: Font: } 2 \text { pt, Bold, } \\
\text { Complex Script Font: Italic }\end{array}$ \\
\hline $\begin{array}{l}\text { Formatted: Normal, Left, Space } \\
\text { Before: } 0 \text { pt, After: } 0 \text { pt, Line } \\
\text { spacing: single }\end{array}$ \\
\hline $\begin{array}{l}\text { Formatted: Font: } 11 \text { pt, Not Bold, } \\
\text { Complex Script Font: } 11 \text { pt }\end{array}$ \\
\hline $\begin{array}{l}\text { Formatted: Font: } 11 \text { pt, Complex } \\
\text { Script Font: } 11 \mathrm{pt}\end{array}$ \\
\hline $\begin{array}{l}\text { Formatted: Font: } 11 \mathrm{pt} \text {, Not Bold, } \\
\text { Complex Script Font: } 11 \mathrm{pt}\end{array}$ \\
\hline $\begin{array}{l}\text { Formatted: Font: } 11 \text { pt, Not Bold, } \\
\text { Complex Script Font: } 11 \mathrm{pt}\end{array}$ \\
\hline $\begin{array}{l}\text { Formatted: Font: } 11 \text { pt, Not Bold, } \\
\text { Complex Script Font: } 11 \text { pt }\end{array}$ \\
\hline ... rmatted \\
\hline ... rmatted \\
\hline ... rmatted \\
\hline ... rmatted \\
\hline ... rmatted \\
\hline ... rmatted \\
\hline ... rmatted \\
\hline ... rmatted \\
\hline ... rmatted \\
\hline ... rmatted \\
\hline ... rmatted \\
\hline ... rmatted \\
\hline
\end{tabular}

A MICROSIMULATION APPROACH TO EVALUATE OPERATIONS OF WEAVING SECTIONS AT URBAN UNCONV INTERSECTIONS IN CAIRO

Soliman, A.K. and Abo Hashema, M.A.Soliman, A.K. and Abo Hashema, M.A. 1

As a consequence of implementing this type of design, direct left turning vehicl minor street are forced to make a right turn followed by a U-turn (RTUT). On the otl minor through traffic (\% Mi THR) are forced to make a RTUT and then a right turn ( the minor street, downstream of the U-turn crossover. Left turning traffic of the mi must also utilize the median side lanes to make a U-turn followed by a right turn (UT the minor approach. The RTUT movement requires a series of lane changes to reach most lane towards the U-turn crossover; similarly, UTRT movement must change reach the outer lane toward the downstream minor approach.

Figure 2 shows a close up of the analysed intersection, and illustrates the formatic urban weaving sections resulting from the local intersection treatment. Ramp to ran and ramp to arterial (R-A) flow components are also shown in the figure.

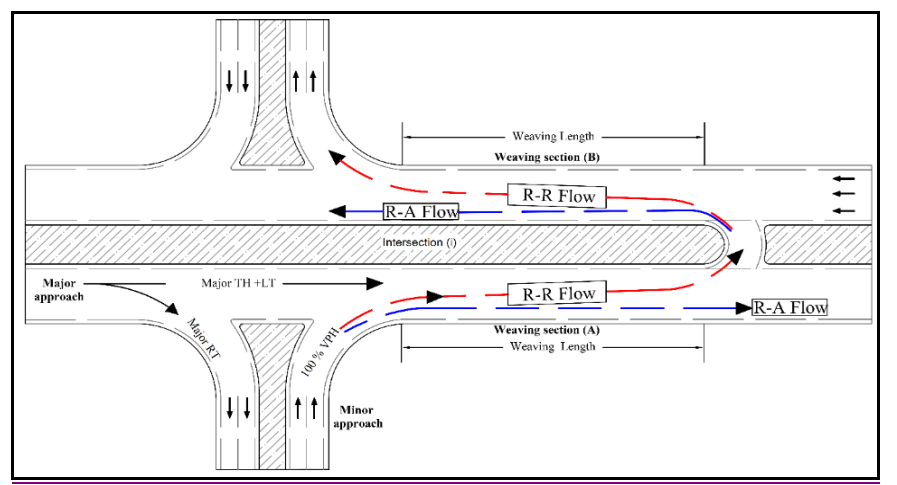

Figure 222: Formation of weaving sections at intersection (i) and flow components.

Most of the weaving related research focused on freeway weaving sections due to the com analyzing operations with interruptions to the traffic flow. In urban, environments, disturban traffic flow could be caused by various elements, such as cross street access, driveways, traffi yield control, stop signs, pedestrians, on street parking, etc. Despite, being the latest state transportation document, the highway capacity manual (HCM 2010) [1], also stops addressing weaving in urban areas and provides a methodology limited to freeway cr Practitioners use the HCM 2010 methodology to design and analyze alternative weaving However, using it to address urban sections is controversial.

To date, there has not been a recognized procedure for the analysis of urban weaving However, simulation seems to be a reliable and sophisticated analysis approach that is ex used nowadays to address limitation of available methodologies and evaluate compls phenomenon. Hence, a simulation approach using VISSIM microscopic simulator was adopt research to address urban weaving sections.

VISSIM is a sophisticated time step and behavioral based simulation model developed to mo traffic, public transit and pedestrian flow. VISSIM offers flexibility in several respects. The $s$ programmability overcomes the limitation of the graphical interface. In addition, the concer and connectors allows users to model geometries with any level of complexity.

4 . The objective of this paper is to evaluate the capacity of Urban weaving sectic simulation models and test the appropriateness of using the HCM methodology to pr operational measures namely; capacity, lane change rates ,speed. The paper also presents ar develop several capacity predictions models and calibrate the Speed prediction algorithms 2010 using the simulation data.
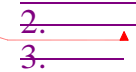


\section{Formatted: Font: 8 pt, Not Bold \\ Formatted: Font: 8 pt, Not Bold \\ Formatted: Font: (Default) Times New Roman}

Formatted: Complex Script Font: Times New Roman

Formatted: Font: (Default) Times New Roman, Complex Script Font: Times New Roman

Formatted: Complex Script Font: Times New Roman

Formatted: Font: 14 pt, Not Bold, Complex Script Font: Times New Roman

Formatted: Complex Script Font: Times New Roman

Formatted: Complex Script Font Times New Roman

Formatted: Complex Script Font Times New Roman

Formatted: Font: Times New Roman, 12 pt

Formatted: Space Before: $0 \mathrm{pt}$, After: 0 pt, No bullets or numbering

Formatted: Font: Times New

Roman, 12 pt, Font color: Custom Color(RGB $(46 ; 116 ; 181)$ )

Formatted: Font: Times New Roman

Formatted: Font: $11 \mathrm{pt}$, Font color: Auto, Complex Script Font: 11 pt

Formatted: Font: $11 \mathrm{pt}$, Font color: Auto, Complex Script Font: 11 pt

Formatted: Font: $11 \mathrm{pt}$, Font color: Auto, Complex Script Font: 11 pt

Formatted: Font: $11 \mathrm{pt}$

Formatted: Font: 11 pt, Complex Script Font: 11 pt

Formatted: Font: 11 pt, Font color: Auto, Complex Script Font: 11 pt

Formatted: Font: $11 \mathrm{pt}$, Font color: Black, Complex Script Font: 11 pt

Formatted: Font: 11 pt, Complex Script Font: $11 \mathrm{pt}$

\section{rmatted}

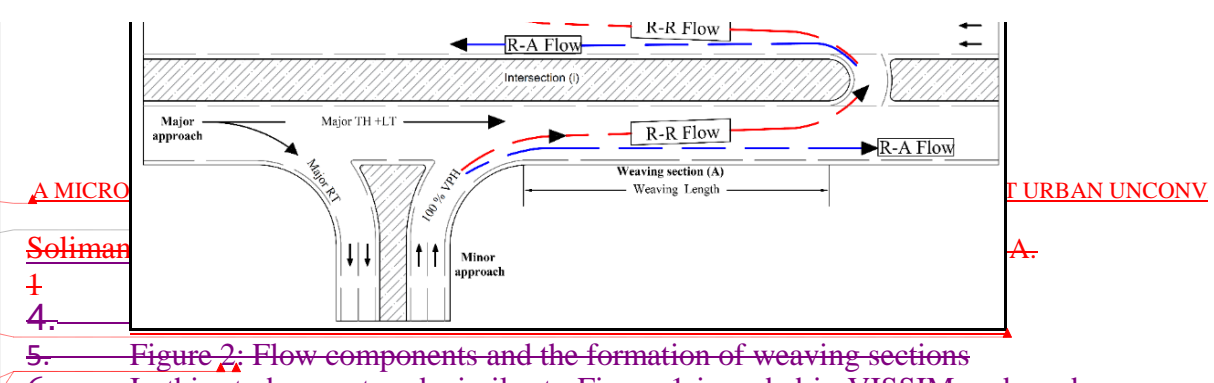

6 . In this study, a network similar to Figure 1 is coded in VISSIM and used as an exp test bed to explore the effects of weaving length, minor demand, major demand and the prer minor through on the operations of weaving section formed at intersection (it) shown in Figt analyse of both intersections and the interactions between all four weaving sections are left study. Figure 2 shows a close up of the analysed intersection and the formation of the sections:

7.

8. At weaving section (A), the miner entrance represents the on ramp and the $U$ turns the off ramp. At weaving section (B), the U turns becomes the on Ramp and the miner downstream is the off ramp. Weaving length is measures as shown in figure 2 for both sectior 9 .

From the HCM 2010 perspective, these local weaving sections are similar eharacteristics to the two sided weaving sections. The HCM 2010 methodelogy states that $i$ two sided weaving sections ramp to ramp movement is the only weaving movement while movements are considered to be non weaving. To maintain consistency with HCM, this resea adopts the same definitions of weaving and non weaving flows

$\rightarrow$ 10. for both of the analysed weaving sections.

\section{BACKGROUND}

Freeway weaving has been a subject of extensive research that -aimed at improving the HCM analysis methodology. Efforts to design and analysis analyze weaving sections trace back to $t$ fifties with the first edition of the highway capacity manual HCM $1950-\mathrm{HCM} \mathrm{1950,}$ contained the first weaving analysis methodology [2]. Later in 1965, the manual was update methodology was enhanced by Jack Leisch [3], introducing who introduced the concept of , realm of weaving and quality of flow, which was later mapped intelevels of services., which mapped into levels of service.

Over the period from 1965 to 1985, new methodologies and approaches emerged as re adopted concepts such as, the proportional use of lanes by weaving and non-weaving andvehicles, and the introduction of geometric configurations. The1985 HCM [4] incorporc new concepts and defined three types of geometric eenfigurationsconfigurations; type A, ty Type C. Further updates were carried out in 1994 and 1997 where coefficients of the speed 1 equations were revised, and the LOS was altered to be dependent on density rather than st HCM 2000 edition-[5] contained further improvements and introduced a multi-page tab] estimating the capacity estimation of weaving sections, which was a major improv methodology.

In 2006, the NCHRP sponsored project 3-75, which lead to the development of a new analysis methodology [6] that was later incorporated in the HCM 2010 [1]. The study uti] modern data using aerial photography and divided weaving sections into one-sided and weaving sections. The new approach relied on the lane changing activity within the weaving reflect the impact of configuration and type of operation on the performance of the section, originally presented by Fazio in 1986 [7]. The methodology also provided a forwardstraightforward equation forequation to the-predict, the capacity prediction-of the section-capacity.

\section{AlthoughSection.}

Although, various methodologies have been established to analyze weaving sections, are commen design elements in the urban roadway system, all previous methodologies haw 
Formatted: Font: 8 pt, Not Bold

Formatted: Font: 8 pt, Not Bold

Formatted: Font: 11 pt, Font color Black, Complex Script Font: 11 pt

Formatted: Font: 11 pt, Complex Script Font: 11 pt

Formatted: Font: 11 pt, Font color: Black, Complex Script Font: 11 pt

Formatted: Font: $11 \mathrm{pt}$

Formatted: Font: 11 pt, Complex

Script Font: $11 \mathrm{pt}$

Formatted: Font: 11 pt, Font color: Auto, Complex Script Font: 11 pt

Formatted: Font: 11 pt, Complex Script Font: 11 pt

Formatted: Font: 11 pt, Font color Auto, Complex Script Font: 11 pt

Formatted: Font: 11 pt, Complex Script Font: 11 pt

Formatted: Font: $11 \mathrm{pt}$

Formatted: Font: 11 pt, Complex

Script Font: 11 pt

Formatted: Font: 11 pt, Font color: Auto, Complex Script Font: 11 pt

Formatted: Font: $11 \mathrm{pt}$

Formatted: Font: $11 \mathrm{pt}$, Font color: Auto, Complex Script Font: 11 pt

\begin{tabular}{|l|l|}
\hline$\ldots$. & rmatted \\
\hline$\ldots$ & rmatted \\
\hline Formatted: Font: $11 \mathrm{pt}$ \\
\hline$\ldots$ & rmatted \\
\hline$\ldots$ & rmatted \\
\hline$\ldots$ & rmatted \\
\hline
\end{tabular}

\begin{tabular}{|l|l|}
\hline Formatted: Font: $11 \mathrm{pt}$ \\
\hline$\ldots$ & rmatted \\
\hline$\ldots$ & rmatted \\
\hline$\ldots$ & rmatted \\
\hline$\ldots$ & rmatted \\
\hline$\ldots$ & rmatted \\
\hline Formatted: Font: $11 \mathrm{pt}$ \\
\hline$\ldots$ & rmatted \\
\hline$\ldots$ & rmatted \\
\hline
\end{tabular}

A MICROSIMULATION APPROACH TO EVALUATE OPERATIONS OF WEAVING SECTIONS AT URBAN UNCONV INTERSECTIONS IN CAIRO Soliman, A.K. and Abo Hashema, M.A.Soliman, A.K. and Abo-Hashema, M.A 4

on freeway sections where vehicles operate under uninterrupted flow conditions and access to ramp locations only. Interrupted flow conditions on the other hand are more complex to However, traffic simulation is widely used as an alternative analysis tool to efficiently eomplex traffic operations of real world physieal systems using a computer program,s modeling has proven to be a reliable alternative analysis tool that allows researchers to explos traffic phenomenon and conduct experimental analysis with real life or synthetic data computer program.

WEAVSIM is a microscopic freeway simulation program designed specifically for $\mathrm{s}$ weaving sections_[8]. WEAVSIM $\mathbf{A}_{\mathbf{A}}$ was used to investigate the effect of different arrival spee overall speed and delay of ramp weaving sections and develop a regression model to predict measures of performance using a total of 243243 experimental simulation runs [8].

INTRAS is a stochastic vehicle specific time stepping simulation model devel Wicks and Lieberman [9]. Skabardonis, et al (1989) utilized INTRAS to simuli weavingfreeway-weaving sections in California with various types of geometric configurat researchers were able to predict weaving and non-weaving speeds that closely matched field Fazio et al. (1990) also used INTRAS to simulate weaving sections and proposed the use c conflicts as a measure of effectiveness for weaving sections modelling instead of speed [11].

FRESIM is a simulation model enhanced and reprogrammed from its predecessor, INT includes enhancements to it's geometric and operational capabilities [12]. For urban at another simulator called NETSIM was design to be more compatible with the characteristics areas [13]. Nowlin (1998) used NETSIM to analyze urban two-sided weaving sections on frontage roads. He used data from multiple simulations to develop a density prediction $\mathrm{m}$ managed to set recommendations on the minimum and desired weaving length [14].

INTEGERATION is a microscopic model developed by Michael Van Aerade [15]. Ster (1996) estimated Capacities of the weaving sections using INTEGERATION and stated that length affects capacity only for shorter weaving sections, while the number of lanes is the mc factor affecting capacity [16]. Zhang \& Rakha (2010) Used INTEGERATION to perform $\varepsilon$ analysis of three weaving sections in Toronto, Canada and managed to obtain simulated estimates that closely matched field capacities. The study also found that weaving rat influenced the capacity even though it is not accounted forneglected in the HCM2000 model I

VISSIM is a microscopic time step and behavioral based simulation model developed to urban raffic andtraffic, -public transport operations, and flows of pedestrians [18]. The $n$ developed at the University of Karlsruhe in Germany based on the work of R. Wiedemann [1 al (2007) used VISSIM to simulate a type B, six lane weaving section in Emeryville, Califor: extremely detailed data provided by the next generation simulation team (NGSIM). The re also and used output data to generate speed-flow relationships and estimate capacities acc The study further investigated speed-flow relationships at different volume ratios and $\mathrm{f}_{\mathrm{r}}$ capacities decrease noticeably with the increase in volume ratio [20].

Another study by Fitzpatrick (2011) utilized VISSIM to investigate relationships between length, speed, and overall vehicle operations for successive ramps on Texas freeways [21. VISSIM model was calibrated and used as an experimental test bed for a total of $\mathbf{3 6 0}$ : Factors that were used to design the experiment were traffic volume, weaving length, post and proportion of volumes. Evaluation of the simulation data revealed that weaving length is significant variable in predicting speed when included as a continuous variable that assume relationship between speed and weaving length. The study provided guidance on recol distances between ramps and used simulation and field data to develop a speed prediction ec function of geometry and traffic.

Liu et al (2012) used VISSIM to model the impact of cross weave maneuvers on the s capacity of freeways with managed Lanes [22]. The cross weave-weaving maneuver is is - 
Formatted: Font: 8 pt, Not Bold

Formatted: Font: 8 pt, Not Bold

Formatted: Font: $11 \mathrm{pt}$, Font color: Auto, Complex Script Font: 11 pt

Formatted: Font: $11 \mathrm{pt}$, Font color: Auto, Complex Script Font: 11 pt

Formatted: Font: $11 \mathrm{pt}$

Formatted: Font: $11 \mathrm{pt}$, Font color: Auto, Complex Script Font: 11 pt

Formatted: Font: 11 pt, Font color: Auto, Complex Script Font: 11 pt

Formatted: Space Before: $0 \mathrm{pt}$, After: 0 pt, No bullets or numbering

Formatted: Font: 11 pt, Font color Auto, Complex Script Font: 11 pt

Formatted: Font: $11 \mathrm{pt}$

Formatted: Font: $11 \mathrm{pt}$, Font color: Auto, Complex Script Font: 11 pt

Formatted: Font: $11 \mathrm{pt}$, Font color: Auto, Complex Script Font: 11 pt

Formatted: Font: $11 \mathrm{pt}$

Formatted: Space After: 0 pt, Line spacing: Exactly $12 \mathrm{pt}$

Formatted: Font: $11 \mathrm{pt}$, Font color: Auto, Complex Script Font: 11 pt

Formatted: Font: $11 \mathrm{pt}$, Font color: Auto, Complex Script Font: 11 pt

Formatted: Font: $11 \mathrm{pt}$, Font color: Auto, Complex Script Font: 11 pt

Formatted: Font: Times New Roman, 12 pt, Font color: Black, Complex Script Font: 12 pt

Formatted: Space Before: $0 \mathrm{pt}$, After: 0 pt, Line spacing: Exactly $12 \mathrm{pt}$

Formatted: Font: Times New Roman, 12 pt, Bold, Font color: Black, Complex Script Font: 12 pt

Formatted: Font: 11 pt, Not Bold, Complex Script Font: 11 pt

rmatted
rmatted
rmatted
rmatted

A MICROSIMULATION APPROACH TO EVALUATE OPERATIONS OF WEAVING SECTIONS AT URBAN UNCONV INTERSECTIONS IN CAIRO Soliman, A.K. and Abo Hashema, M.A.Soliman, A.K. and Abo Hashema, M.A.

1

the two--sided weaving maneuver described in the HCM 2010. A test bed VISSIM model w: carry out multiple runs with different levels of mainstream demand, cross-weave demand, $\mathrm{m}$ number of lanes, and minimum lane changing distance (LCW-min). Speed-flow curves were using Van Aerde's Curve-curve fitting and capacities were estimated for each scenarioacc The researchers also developed a simulation based regression model to predict the reducti weaving section capacity as a function of cross weave flow rate, number of mainstream 1 weaving length with $\mathrm{R}^{2}$ of 0.9837 indicating a perfect fit.

It was concluded that the simulation appreach is very reliable and allows researchers t various traffic phenemenon and conduct experimental analysis with real life or synthetic data Based on the comparisons and-finding of previous researches, VISSIM traffic simulator $\mathrm{f}_{\mathrm{f}}$ appeared to be the most suitable software for this research due to its modeling flexil capabilities in conducting weaving related studies of freeway and urban sections.

13.

14.

\section{METHODOLOGY}

The methodology adopted herein, is an experimental analysis with synthetic demands using microscopic simulation models to simulate urban weaving sections, resulting fromintersection design-under various combinations of weaving lengths and volume demander The simulations were conducted using the default parameters of the urban driver behavior in -

Experimental analysis often involves the investigation of numerous scenarios. However, doesn't provide a scenario manager where one could predefine all the scenarios and-allc model-program to run them in sequence; therefore, an external programme called AUTOI was developed in visuat-Visual basic-Basic programming language to automate the simulc through the COM interface feature provided by VISSIM.

The experimental designs allowed the simulation of the weaving sections at different weavir and under-various levels of demand inputs-input and volume ratios. Some of these dem: combinations caused the weaving sections to reach eapacity whichcapacity, which was pc eut. After capacities were derived, using the simulation, -SPSS statistical package was-is i derive-develop sSimulation based logarithmic and linear capacity prediction models for the urban weaving sections.

Finally, $\mathrm{tFo}$ test the reliability of the HCM 2010 weaving analysis methodology was methodology applied to the each weaving section to test the methodology's reliability in ref urban weaving operations, the methodology was applied to the local weaving sections keyKey weaving operational measures were predicted using the HCM methodology namely:; lane change rates, weaving and non-weaving speeds. These predicted measures were -were-1 to those of the Simulation-simulation models using statistical and graphical methods. Finally, was undertakenwas made to calibrate and modify the investigate the-HCM 2010 speed 1 models in representing urban weaving operations when calibrated using non linear regression using the simulation data points to reflect urban conditions.

\section{$\rightarrow 3.1$ sSimulated network}

$\rightarrow$ In this study, a network similar to Figure 1 was coded in VISSIM to serve as an experiment $\varepsilon$ to explore the effects of weaving length, minor demand, major demand and the percentage through split on the operations of weaving section (A) and (B) as shown in Figure 2.

$\rightarrow$ The simulated network is similar to the network illustrated in Figure 1. It Consists of two-e at grade intersections, $1 \mathrm{~km}$ apart. The simulated network depicts a typical intersection desi 


\section{Formatted: Font: 8 pt, Not Bold \\ Formatted: Font: 8 pt, Not Bold}

\section{rmatted}

Formatted: Font: Times New Roman, 11 pt, Not Bold, Font color: Black, Complex Script Font: $11 \mathrm{pt}$

Formatted: Space After: 0 pt rmatted

Formatted: Font: Bold, Font color Black

Formatted: Font: (Default) Times New Roman, 12 pt, Bold, Font color: Black, Complex Script Font: Times New Roman, 12 pt

\begin{tabular}{|c|}
\hline ... rmatted \\
\hline ... rmatted \\
\hline ... rmatted \\
\hline ... rmatted \\
\hline Formatted: Font color: Black \\
\hline ... rmatted \\
\hline ... rmatted \\
\hline ... rmatted \\
\hline Formatted: Font color: Black \\
\hline ... rmatted \\
\hline ... rmatted \\
\hline ... rmatted \\
\hline Formatted: Font color: Black \\
\hline ... rmatted \\
\hline Formatted: Font color: Black \\
\hline ... rmatted \\
\hline Formatted: Font color: Black \\
\hline ... rmatted \\
\hline Formatted: Font color: Black \\
\hline ... rmatted \\
\hline Formatted: Font color: Black \\
\hline ... rmatted \\
\hline Formatted: Font color: Black \\
\hline ... rmatted \\
\hline
\end{tabular}

A MICROSIMULATION APPROACH TO EVALUATE OPERATIONS OF WEAVING SECTIONS AT URBAN UNCONV INTERSECTIONS IN CAIRO

Soliman, A.K. and Abo Hashema, M.A.Soliman, A.K. and Abo Hashema, M.A.

4

widely adopted at major intersections corridors in the city of Cairo. There is no traffic control the conflict points; however, yield control is applied at the U-turns and at the major ints through a combination of conflict areas and priority rules features provided by VISSIM.

$\rightarrow$-The main stream has 3 lanes each lane is 3.65 meter wide, while the minor approaches hav $3.65 \mathrm{~m}$ each also 3.65 meter wide. U-turn slot is a single lane without any acceleration or der bays at_any point. The posted speed limit is $60 \mathrm{~km} / \mathrm{hr}$ and a turning speed of $2 \mathrm{C}$ assumed $\longrightarrow$ for all vehicles. This study focuses on the andysis of the twe sections that are formed at one of the intersections only. The study also assumed simila eonditions at both intersections. The simulations were conducted using the default paramet urban driver behavior in VISSIM.

$\rightarrow 15.2$ experimentalExperimental design

$\rightarrow$ A general factorial design was adopted. The influential factors chosen for the experiment weaving length (WL), the minor approach demand, the major approach demand, and the $\mathrm{F}$ percentage of minor through split (\% Mi THR).

Weaving length (WL), is was measured as shown in Figure 2 with four levels starting meters to 400 meters with a 100 -meter increment

The Next consecutive set of weaving sections are similar to weaving section (A) and (B) in and volume conditions; therefore, these sections are excluded from the research analysis,

Hypothetical traffic volumes were used in this e current-study. Minor approach ranged from $100 \mathrm{vph}$ to $2000 \mathrm{vph}$, with a $100 \overline{\mathrm{vph}}$ increment up to a level of 1000 then the increment is increased to $200 \mathrm{vph}$ (i.e. 15 volume levels). Major approach ranged from $1000 \mathrm{vph}$ to $2400 \mathrm{vph}$, with a $200 \mathrm{vph}$ increment (i.e. 8 volume levels ranges were chosen based on the observed animations of a few trial simulations with low volume conditions to guarantee that these volumes covered a wide range of $s$. levels.

All minor approach volume scenarios were modeled with $20 \%$ left turn volumes. The major was modeled with a $10 \%$ major LT and $20 \underline{10} \%$ major RT. The major approach right turns into two $10 \%$ right turns for each intersection.

Minor appreach-through split (\% Mi THR) waswas -defined as $25 \%$ of the minor approacl for the first minor through split levelsplit-level, (\% Mi THR) and then increased to 50 minor demand for the second level of (\% Mi THR). i.e. (miner traffic splits $=25 \% \mathrm{~T}$ LT, 55\% RT) and then changed to $50 \%$ of the minor demand for the second level i.e. (mir splits $=50 \%$ THR, 20\% LT, 30\% RT)

ChangingIncreasing the minor through - wassplit was intended to increase thee int weaving-traffic.. Increasing the minor through from $25 \%$ to $50 \%$ increases the perce ramp to rampramp-to-ramp vehicles from $45 \%$ to $70 \%$ of the minor demand ${ }_{\omega}$-approac

In total, 960 combination runs were generated using a general factorial design-provided by $\mathrm{A}$ statistical package. - Each weaving length had 120 combination runs for each level of the $\%$ split (Mi THR $=25 \%$ and Mi THR $=50 \%)$.

Weaving section of different length and traffic splits required different configurations,configurations; therefor, two test beds corresponding to both lev Mi THR split for each weaving section length was-were coded. In total 8 VISSIM models were prepared to run 120 combinations of minor and major volume levels. 


\begin{tabular}{|l|}
\hline Formatted: Font: 8 pt, Not Bold \\
\hline Formatted: Font: 8 pt, Not Bold \\
\hline
\end{tabular}

Formatted: Space Before: 0 pt, After: 0 pt, No bullets or numbering

Formatted: Font: Times New Roman, 11 pt, Not Bold, Font color: Auto

Formatted: Font: Times New Roman, Not Bold, Font color: Auto

Formatted: Font: Times New Roman, 11 pt, Not Bold, Font color: Auto

Formatted: Font: Times New Roman, Not Bold, Font color: Auto

Formatted: Font: Times New Roman, 11 pt, Not Bold, Font color: Auto

Formatted: Font: Times New Roman, Not Bold, Font color: Auto

Formatted: Font: Times New Roman, 11 pt, Not Bold, Font color: Auto

Formatted: Font: Times New Roman, 11 pt, Not Bold, Font color: Auto, Complex Script Font: $12 \mathrm{pt}$

Formatted: Font: $10 \mathrm{pt}$

Formatted: Font: Times New Roman, Not Bold, Font color: Auto

Formatted: Font: Times New Roman, Font color: Auto

Formatted: Font: Times New Roman, Not Bold, Font color: Auto

Formatted: Font: Times New Roman, 12 pt, Not Bold, Font color: Auto, Complex Script Font: $12 \mathrm{pt}$

Formatted: Font: $5 \mathrm{pt}$

Formatted: Centered, Space Before: 0 pt, After: 0 pt

\section{rmatted}

\section{rmatted}

Formatted: Tab stops: Not at 82.5 $\mathrm{mm}+165.1 \mathrm{~mm}$
A MICROSIMULATION APPROACH TO EVALUATE OPERATIONS OF WEAVING SECTIONS AT URBAN UNCONV INTERSECTIONS IN CAIRO

Soliman, A.K. and Abo Hashema, M.A.Soliman, A.K. and Abo Hashema, M.A. 4

\section{$\rightarrow$ 15.3 Automation automation-program development}

All 960 scenarios generated by the factorial design were simulated using PTV-VISSIM ttraffic simulator through an external program developed in visual basic script. E- each needed to be run 3 times with different random number seeds makingseeds, which makes it 28802880 runs. This would have been very time consuming, therefore efficiency required at of the process using computer programming.

s.

A computer program called AUTOMATE was developed using Excel Visual Basic : automate the scenario runs generated by the factorial design. The program simply changes and minor demand volume for each iterationiteration (scenario) automatically using a visual next loop. Once iterations are completed, the program moves to another network and th repeated again until all networks are have been-processed. Figure 3 depicts a flow chart that the logic of the developed program where each iteration (scenario) has a unique run order. the

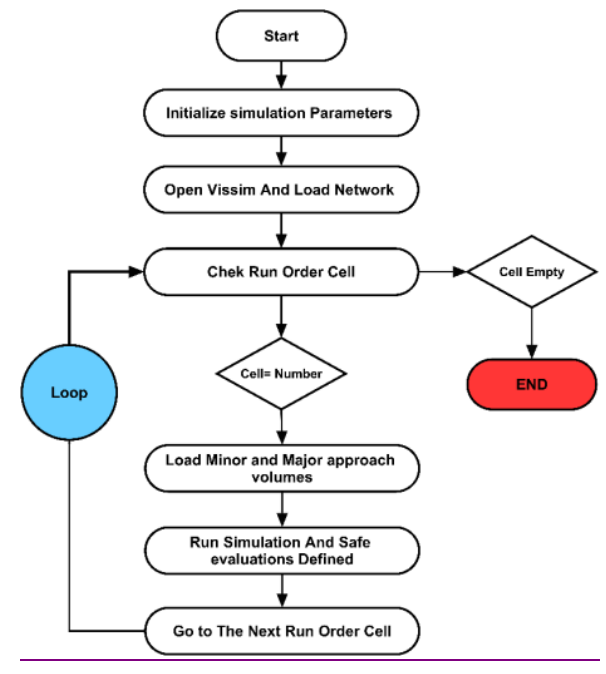




\begin{tabular}{|l|}
\hline Formatted: Font: 8 pt, Not Bold \\
\hline Formatted: Font: 8 pt, Not Bold \\
\hline $\begin{array}{l}\text { Formatted: Font: Times New } \\
\text { Roman, } 10 \text { pt, Font color: Black }\end{array}$ \\
\hline $\begin{array}{l}\text { Formatted: Font: Times New } \\
\text { Roman, } 10 \text { pt, Font color: Black }\end{array}$ \\
\hline Formatted: Font color: Black \\
\hline $\begin{array}{l}\text { Formatted: Font: Times New } \\
\text { Roman, } 10 \text { pt, Font color: Black }\end{array}$ \\
\hline $\begin{array}{l}\text { Formatted: Font: } 10 \mathrm{pt} \text {, Font color: } \\
\text { Black }\end{array}$ \\
\hline
\end{tabular}

Formatted: Centered, Space Before: $0 \mathrm{pt}$, After: $0 \mathrm{pt}$, Line spacing: single

Formatted: Font: Times New Roman, $10 \mathrm{pt}$

Formatted: Font: Times New Roman, 10 pt, Font color: Black

Formatted: Font color: Black

Formatted: Font: Times New Roman, 10 pt, Font color: Black

Formatted: Font: Times New Roman, 10 pt, Bold, Font color: Black

Formatted: Tab stops: Not at 82.5 $\mathrm{mm}+165.1 \mathrm{~mm}$
A MICROSIMULATION APPROACH TO EVALUATE OPERATIONS OF WEAVING SECTIONS AT URBAN UNCONV INTERSECTIONS IN CAIRO

Soliman, A.K. and Abo Hashema, M.A.Soliman, A.K. and Abo Hashema, M.A.

4

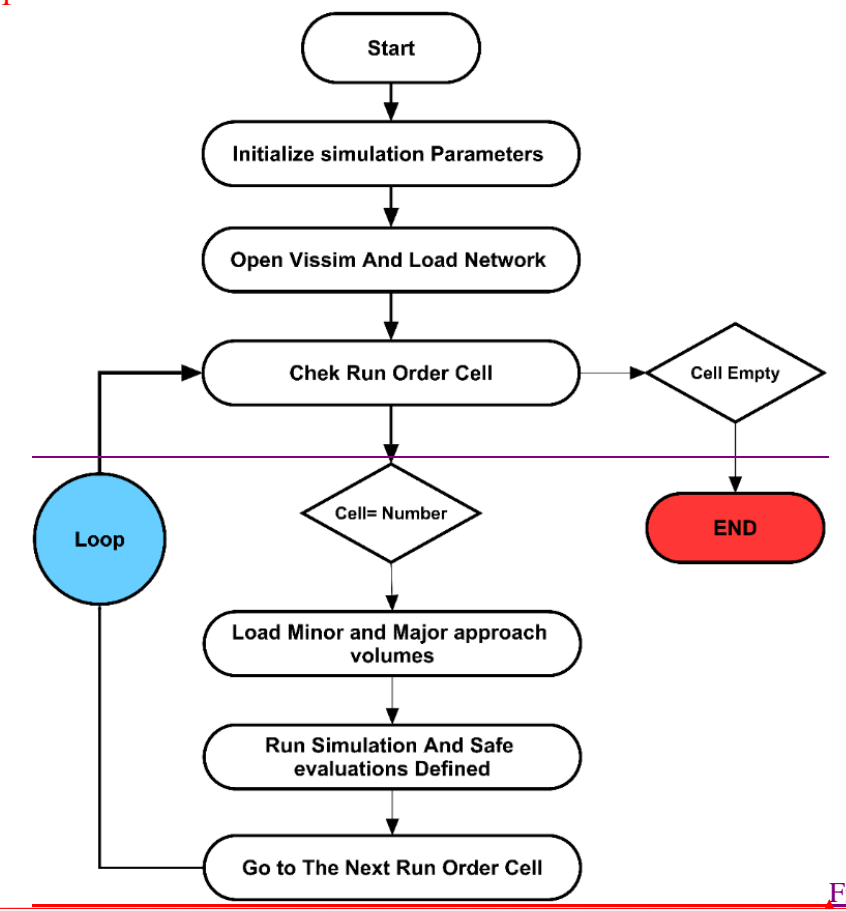

AUTOMATE

Figure. 3: Logic of the VBA r

\section{WEAVING SECTION MODELLING}

The VISSIM network is modeled using a system of links and connectors. Conflict priority rules were used to accurately depict the interaction between crossing streams. Vehi in (vph) were loaded and changed automatically by the developed VBA program. T program immediately loads the predefined network and then the vehicle input ( VISSIM is accessed through COM interface to assign vehicle inputs at the proper chos The assigned vehicle input value corresponds to a specific run (scenario) accordin matrix generated by factorial design and embedded within the program. Static routing to route vehicles from a start point (red) to any of the defined destinations (green) usin: percentage for each destination. Routing decisions are similar for each VISSIM network. shows all routing decisions as specified in VISSIM and Table 1 summarizes the traffic spli route.

Fig. 3: Routing decisions as modeled in VISSIM

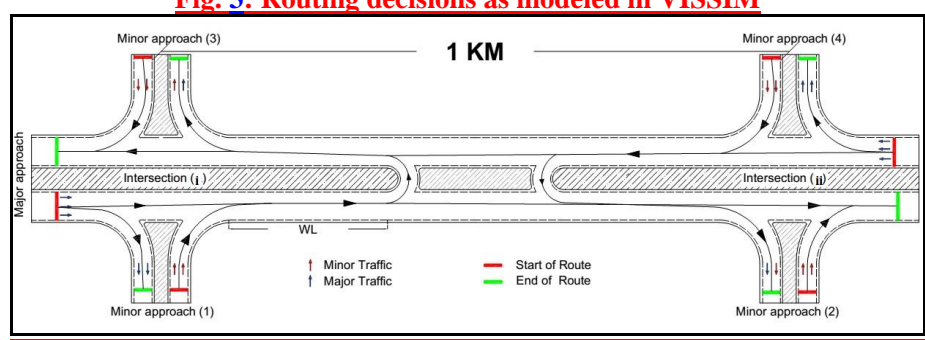

Figure 3: Logic of the AUTOMATE program for automation of simulation runs, 


\begin{tabular}{|c|}
\hline ... rmatted \\
\hline ... rmatted \\
\hline ... rmatted \\
\hline ... rmatted \\
\hline ... rmatted \\
\hline ... rmatted \\
\hline ... rmatted \\
\hline ... rmatted \\
\hline ... rmatted \\
\hline ... rmatted \\
\hline ... rmatted \\
\hline ... rmatted \\
\hline$\ldots$ rmatted \\
\hline ... rmatted \\
\hline ... rmatted \\
\hline ... rmatted \\
\hline ... rmatted \\
\hline ... rmatted \\
\hline ... rmatted \\
\hline$\ldots$ rmatted \\
\hline ... rmatted \\
\hline ... rmatted \\
\hline ... rmatted \\
\hline$\ldots$ rmatted \\
\hline ... rmatted \\
\hline ... rmatted \\
\hline ... rmatted \\
\hline ... rmatted \\
\hline ... rmatted \\
\hline ... rmatted \\
\hline ... rmatted \\
\hline ... rmatted \\
\hline ... rmatted \\
\hline ... rmatted \\
\hline ... rmatted \\
\hline ... rmatted \\
\hline ... rmatted \\
\hline ... rmatted Table \\
\hline ... rmatted \\
\hline ... rmatted \\
\hline
\end{tabular}
Soliman, A.K. and Abo Hashema, M.A.Seliman, A.K. and $A b \theta$ Hashema, M.A. 1

$\rightarrow$ W6. WEAVINGSECTIONMODELLING

The VISSIM network is modeled using a system of links and connectors .connectors areas and priority rules were used to accurately depict the interaction between crossing Vehicle inputs in (vph) $\mathrm{vph}$ ) were loaded and changed automatically by the develop program AUTOMATE.

The-:-

The VBA program immediately loads the predefined network and then and acce Vehicle input object in VISSIM is accessed through COM interface to assign vehicle the proper proper chosen links. The assigned vehicle input value corresponds to a sp€
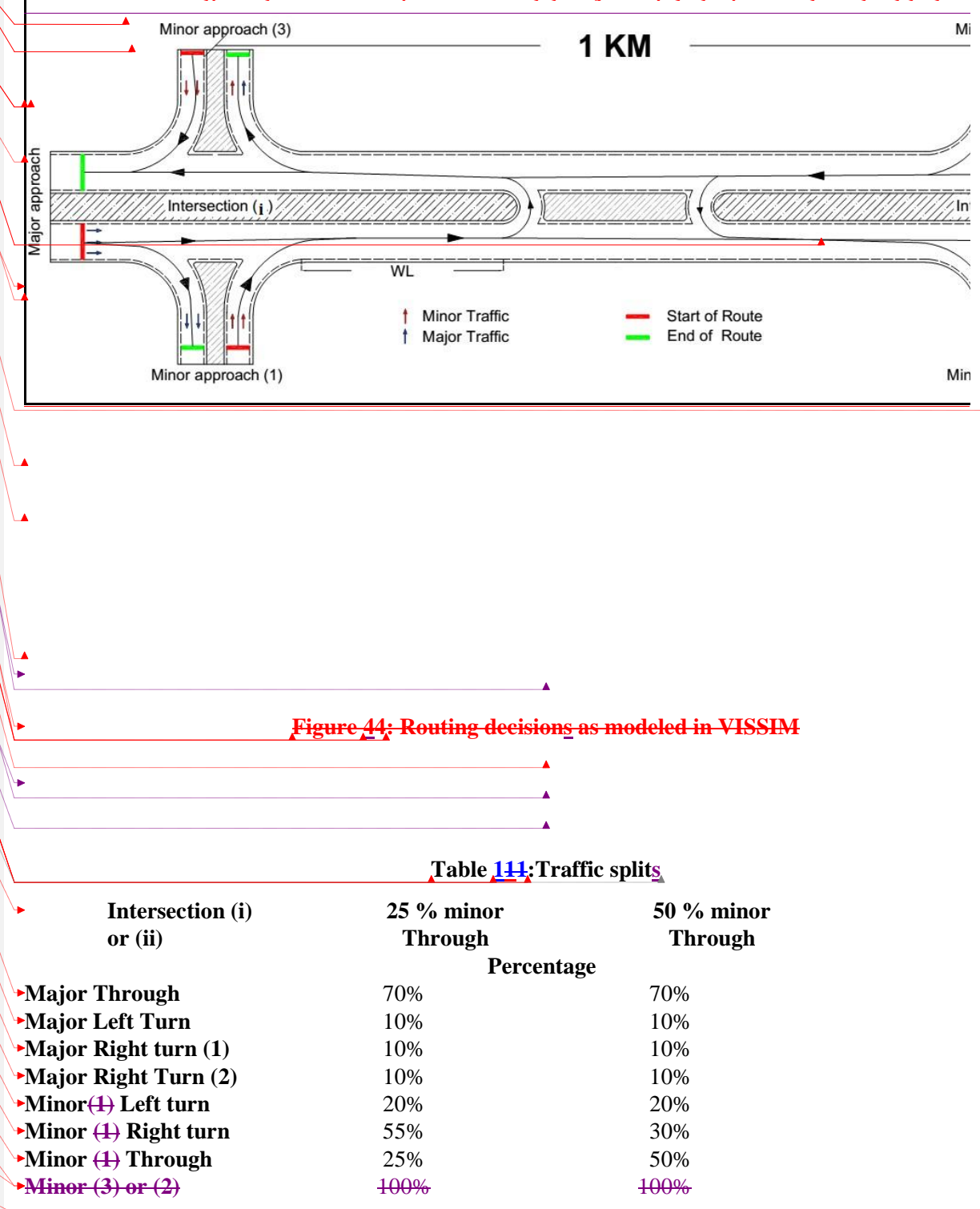


\begin{tabular}{|l|}
\hline Formatted: Font: 8 pt, Not Bold \\
\hline Formatted: Font: 8 pt, Not Bold \\
\hline $\begin{array}{l}\text { Formatted: Font: Times New } \\
\text { Roman }\end{array}$ \\
$\begin{array}{l}\text { Formatted: Space After: } 0 \text { pt, Line } \\
\text { spacing: Exactly } 12 \text { pt }\end{array}$ \\
$\begin{array}{l}\text { Formatted: Line spacing: Exactly } \\
12 \text { pt }\end{array}$ \\
\hline $\begin{array}{l}\text { Formatted: Font: Times New } \\
\text { Roman }\end{array}$ \\
\hline
\end{tabular}

Formatted: Space After: 0 pt, Line spacing: Exactly $12 \mathrm{pt}$

\section{Formatted: Indent: Before: 6.3 $\mathrm{mm}$, Space After: $0 \mathrm{pt}$, Line spacing: Exactly $12 \mathrm{pt}$}

Formatted: Font: 1 pt, Not Bold, Font color: Auto

Formatted: Indent: Before: 12.7 $\mathrm{mm}$, Space After: $0 \mathrm{pt}$, Line spacing: single, No bullets or numbering

Formatted: Font: Times New Roman, 1 pt, Not Bold, Font color: Auto

Formatted: Font: Times New Roman, 1 pt

Formatted: Font: (Default) Calibri 1 pt, Font color: Auto, Complex Script Font: Arial

Formatted: Font: (Default) Calibri, 1 pt, Not Bold, Font color: Auto, Complex Script Font: Arial

Formatted: Font: (Default) Calibri, 1 pt, Font color: Auto, Complex Script Font: Arial

\section{... rmatted}

Formatted: Font: $1 \mathrm{pt}$

Formatted: Left, Indent: Before: $12.7 \mathrm{~mm}$, No bullets or numbering Formatted: Left, Indent: Before: $12.7 \mathrm{~mm}$

Formatted: Font: Times New Roman, 1 pt

Formatted: Normal

Formatted: Tab stops: Not at 82.5 $\mathrm{mm}+165.1 \mathrm{~mm}$
A MICROSIMULATION APPROACH TO EVALUATE OPERATIONS OF WEAVING SECTIONS AT URBAN UNCONV INTERSECTIONS IN CAIRO

Soliman, A.K. and Abo Hashema, M.A.Soliman, A.K. and Abo Hashema, M.A. 4

$\rightarrow$ The percentage of heavy vehicles were assumed $2 \%$ for all cases; therefore, all compositions are were $98 \%$ passenger cars and $2 \%$ heavy vehicles. Each vehicle type had a stochastic distr: desired speed and for this research the speed distribution for cars will-was be $60 \mathrm{~km} / \mathrm{hr}(58 \mathrm{k}$ $\mathrm{km} / \mathrm{hr}$ ) while for the heavy vehicles (HGV) the desired speed distribution will bewas selec $\mathrm{km} / \mathrm{hr}(48 \mathrm{~km} / \mathrm{hr}: 58 \mathrm{~km} / \mathrm{hr})$

$\rightarrow$ VISSIM provides a wide range of evaluations that must be defined and configured in order desired model output from the a simulation run. The common form of these outputs, are of files containing the results and delimited by a semicolon. The period of the each run is se seconds; however, the first 900 seconds were considered warm up and outputs were collect; last 3600 seconds of simulation The.

For this research, -common form of these outputs, are offline text files containing the resultsby a semicelen. Tthe following evaluations were activated and configured in VISSIM:

- Link evaluation: The link evaluation feature allows allows the user to gathercol] simulation results based on the area of the-weaving for the last $3600 \mathrm{sec}$ of the simulc as (density, Throughput, average speed).

- Lane change rates: Allows the collection of the total lane change rates s-executed w: weaving section for the last $3600 \mathrm{sec}$ of the simulation.

- Data collection Points: Collects vehicle counts and spot speeds at the major a entrance upstream of weaving section (A).

- Travel time sections: Allows the collection of travel times and vehicle eeunts-cc user defined travel time section. Travel times sections are set up to capture weaving weaving volumes-flow rates and speeds-speeds as shown Figurein figure 5 as

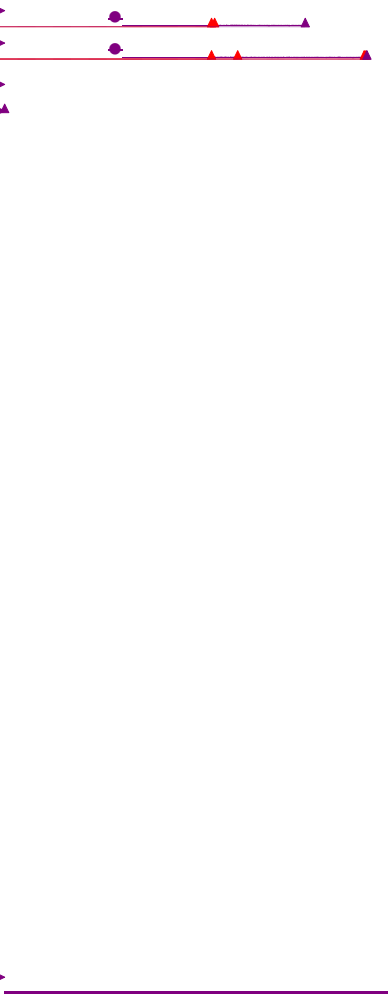




\begin{tabular}{|l|}
\hline Formatted: Font: 8 pt, Not Bold \\
\hline Formatted: Font: 8 pt, Not Bold
\end{tabular}

Formatted: Indent: Before: $0 \mathrm{~mm}$

\begin{tabular}{|c|}
\hline $\begin{array}{l}\text { Formatted: Font: Times New } \\
\text { Roman }\end{array}$ \\
\hline $\begin{array}{l}\text { Formatted: Font: } 10 \mathrm{pt} \text {, Font color: } \\
\text { Black }\end{array}$ \\
\hline $\begin{array}{l}\text { Formatted: Font: } 10 \mathrm{pt} \text {, Font color: } \\
\text { Black }\end{array}$ \\
\hline Formatted: Font color: Black \\
\hline $\begin{array}{l}\text { Formatted: Font: Times New } \\
\text { Roman, } 10 \text { pt, Font color: Black }\end{array}$ \\
\hline $\begin{array}{l}\text { Formatted: Font: Times New } \\
\text { Roman, } 10 \text { pt, Not Bold, Font } \\
\text { color: Black }\end{array}$ \\
\hline $\begin{array}{l}\text { Formatted: Centered, Space } \\
\text { Before: } 0 \text { pt, After: } 0 \text { pt, Line } \\
\text { spacing: Exactly } 12 \mathrm{pt}\end{array}$ \\
\hline $\begin{array}{l}\text { Formatted: Font: Times New } \\
\text { Roman, } 10 \mathrm{pt}\end{array}$ \\
\hline $\begin{array}{l}\text { Formatted: Space Before: } 0 \mathrm{pt}, \\
\text { After: } 0 \mathrm{pt}\end{array}$ \\
\hline $\begin{array}{l}\text { Formatted: Font: } 11 \text { pt, Font color: } \\
\text { Auto, Complex Script Font: } 11 \mathrm{pt}\end{array}$ \\
\hline $\begin{array}{l}\text { Formatted: Font: Bold, Font color: } \\
\text { Black }\end{array}$ \\
\hline $\begin{array}{l}\text { Formatted: Space After: } 0 \text { pt, Line } \\
\text { spacing: Exactly } 12 \mathrm{pt}\end{array}$ \\
\hline $\begin{array}{l}\text { Formatted: Space Before: } 0 \text { pt, } \\
\text { After: } 0 \text { pt, Line spacing: Exactly } \\
12 \text { pt, No bullets or numbering }\end{array}$ \\
\hline $\begin{array}{l}\text { Formatted: Line spacing: Exactly } \\
12 \mathrm{pt}\end{array}$ \\
\hline $\begin{array}{l}\text { Formatted: Tab stops: Not at } 82.5 \\
\mathrm{~mm}+165.1 \mathrm{~mm}\end{array}$ \\
\hline
\end{tabular}

A MICROSIMULATION APPROACH TO EVALUATE OPERATIONS OF WEAVING SECTIONS AT URBAN UNCONV INTERSECTIONS IN CAIRO

Soliman, A.K. and Abo Hashema, M.A.Soliman, A.K. and Abo Hashema, M.A.

1
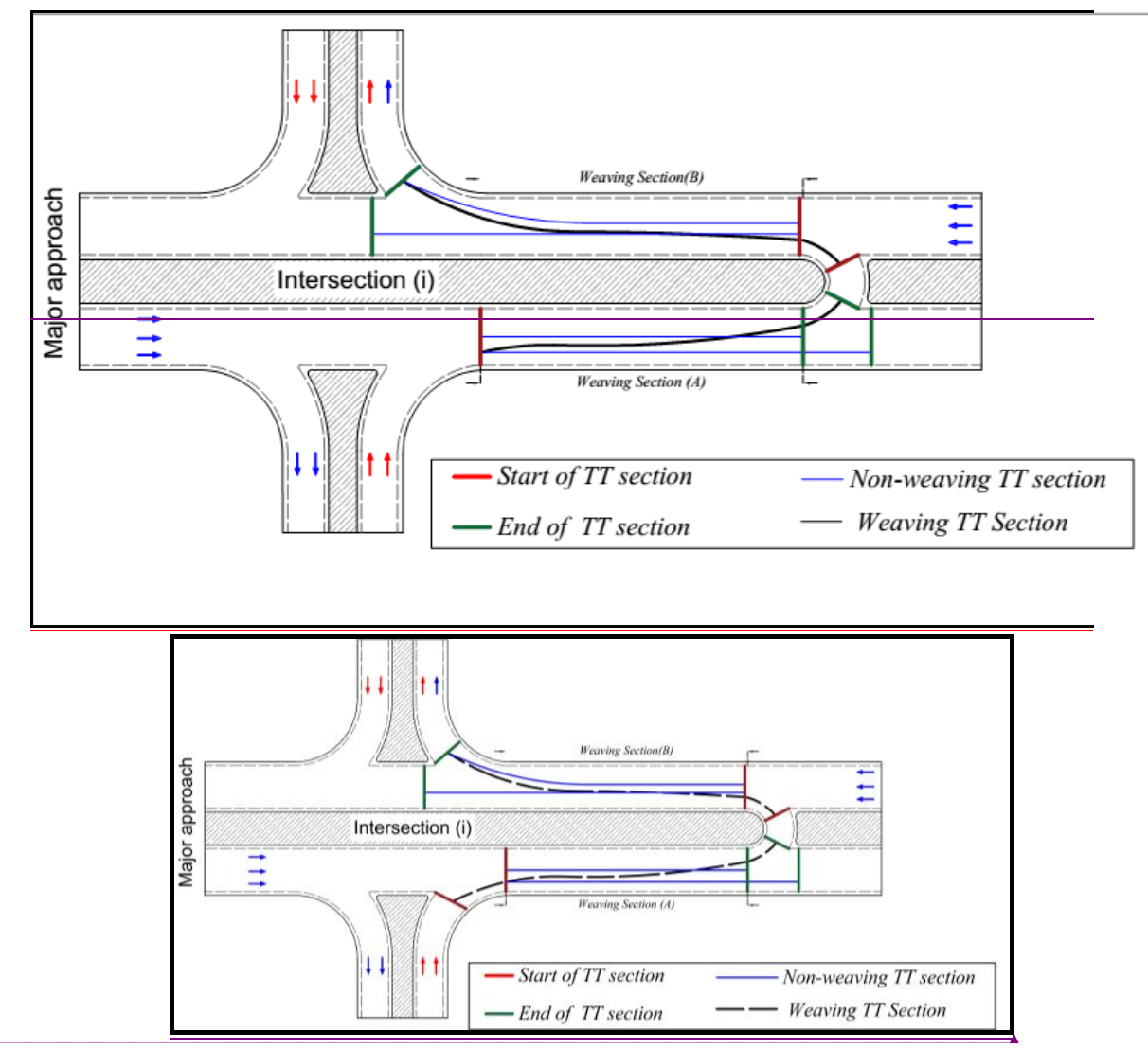

Figure Fig. 4455: Travel time sections as defined in VISSIM

From the HCM 2010 [1] perspective, these local weaving sections are similar in their charact the two-sided weaving sections. The HCM 2010 methodology states that in case of two sided sections the ramp-to-ramp movement is the only weaving movement, while all other move considered non-weaving. To maintain consistency with HCM, this research paper adopts definitions to differentiate between weaving and non-weaving flows. Therefore, travel tim were set accordingly based on the HCM 2010 definitions of weaving and non-weaving mov shown in figure 5, where the dashed line represents the weaving flow and the solid lines repr non-weaving flows.

At weaving section (A), the minor entrance represents the on ramp and the U-turns represer ramp while at weaving section (B), the U-turns becomes the on-Ramp and the minor downstream is the off ramp.

Travel time sections produces the average travel time of a number of vehicles passing a us travel time section with a known distance during a specific time interval. By dividing th travel time by the length of the travel time section, the space mean speed of each movemen calculated.

\section{$\rightarrow 17$ ANALYSIS OF SIMULATION RESULTS}

$\rightarrow$ After 960, simulation runs with 3 different random number seeds were conducted, a tota] evaluation output files were generated for each individual evaluation type previously conf 
VISSIM (link evaluation, lane change rates, travel times, and data collection points). To t extract the simulation output from each file, 4 vistat-Visual basic-Basic programs were deve the extraction and manipulation of the output data.

All-The 4 programs were developed using the same data extraction logic $\overline{;}_{2}$ however, difference is how the data was organized for each evaluation type.

-When executing the program, it automatically prompts the user for the output folder directs choosing the directorydirectory, the program loops through all the output files importing eac] Microsoft excel and extractsextracting the evaluation data. The program also calculates the a each repeated simulation run with different number seeds and preforms any necessary ca such as converting the travel times to into speedsspeeds when extracting the travel timeconverting vehicles into Passenger car equivalents.

Formatted: Space Before: $0 \mathrm{pt}$, After: 0 pt, Line spacing: Exactly $12 \mathrm{pt}$

\section{$\rightarrow$ 5.1 capacityCapacity estimation using simulation}

VISSIM or any other simulation tool does not produce capacity estimates directly. The easie estimate Capacity is to observe the link (Study segment), throughput against an increasin input. The throughput represents the actual vehicles processed by VISSIM, while the represents the vehicle inputs that are assigned to the simulated network.

The-At first, the throughput equals the input demand up to a certain point, and then $]$ indicating that the system is not able to accommodate any more vehicles and is operating at The throughput represents the actual processed vehicles while the demand represents the inputs that are assigned to the simulated network.

It was also expected to observe that the throughput of weaving section (A) is almost eq throughput of section (B). Theoretically, the throughput of weaving section (A), should b equal to the throughput of weaving section $(\mathbf{B})$ assuming similar volume inputs and routing at the next consecutive intersection of the network, in addition to similar number of seeds ( $i$. simulated vehicular arrival times).

-Figures 6 shows the relationship between the total demand and throughput of weaving sectio a 100100 meters and and $200 \mathrm{~m} 200$ meters weaving lengths as an example. From the surfact Figure $6{ }_{2}$ it is noticeable that the throughput increases with the increase in total demand majorMajor) until reaching a certain threshold where it becomes nearly constant and unresf further increase in the continuous ddemand-increase. The point of maximum constant th represents the capacity of the weaving section. The figure also shows that the capacity of the directly proportional to the major demand level and to the weaving length.

From the same figurefigure, it is also noticed that the Throughputthroughput decreases with increase in-minor through traffic split increased from $25 \%$ to $50 \%$. The decrease in cap attributed to the fact that increasing the percentage of minor vehicles through increased the flow from $45 \%$ of the minor demand to $70 \%$ leading to a higher VRvolume ratio (VR), which causes higher lane changing related mulence andurbulence, and lower capacityies.

Figure 7 shows the simulated capacities of all weaving lengths at each major demand lev length was increased beyond 200 meters, the capacities increased with major demand up to point and then started to level after major demand exceeded 2000 and $1600 \mathrm{VPH}$ vph for $50 \%$ Mi THR split, respectively for both weaving sections. 


Formatted: Font: 8 pt, Not Bold
Formatted: Font: 8 pt, Not Bold
spacing: Exactly $12 \mathrm{pt}$

Formatted: Font: $11 \mathrm{pt}$, Font color: Auto, Complex Script Font: 11 pt

Formatted: Font: $11 \mathrm{pt}$, Font color: Auto, Complex Script Font: 11 pt

Formatted: Line spacing: single

Formatted: Font: Times New

Roman

Formatted: Font: Times New

Roman

Formatted: Centered
A MICROSIMULATION APPROACH TO EVALUATE OPERATIONS OF WEAVING SECTIONS AT URBAN UNCONV INTERSECTIONS IN CAIRO

Soliman, A.K. and Abo Hashema, M.A.Soliman, A.K. and Abo-Hashema, M.A

1

It was found that increasing the weaving length beyond 200 meters did not increase the c; the sections, on the contrary capacitiesy was less than the values associated with the shorter length (200 meter-) for major demand levels greater than 2000 and $1600 \mathrm{VPH}-\underline{v p h}$ for $\underline{\text { at }}$ $50 \%$ Mi THR respectively for beth sections.

$\rightarrow$ Capacity difference between sections (A) and (B) for at both eases levels of \% Mi THRTHR $50 \%$ ) was neglectedneglected, as the maximum difference was did not exceed $2.5 \%$ maxif slight variation in throughputs between Weaving section (A) and (B) is only attribut stochastic behaviour of the simulation model. 


\section{Formatted: Font: 8 pt, Not Bold \\ Formatted: Font: 8 pt, Not Bold}

A MICROSIMULATION APPROACH TO EVALUATE OPERATIONS OF WEAVING SECTIONS AT URBAN UNCONV INTERSECTIONS IN CAIRO

Soliman, A.K. and Abo Hashema, M.A.Soliman, A.K. and Abo Hashema, M.A

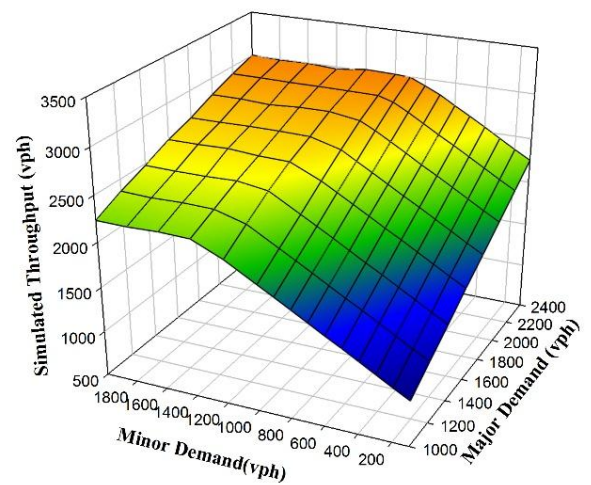

25\% Mi THR

$\begin{array}{ll}500 & \\ 1000 & 2500 \\ 1500 & 3000 \\ 2000 & 3500\end{array}$

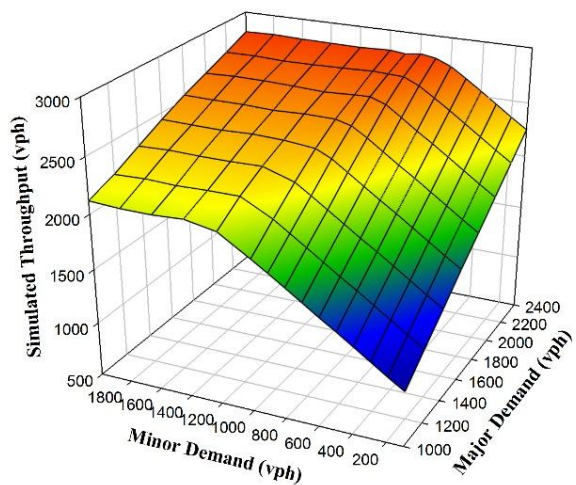

$50 \%$ Mi THR

500
1000
1500 25000

a. Simulated throughput of weaving section (A) at $W L=100 \mathrm{~m}$

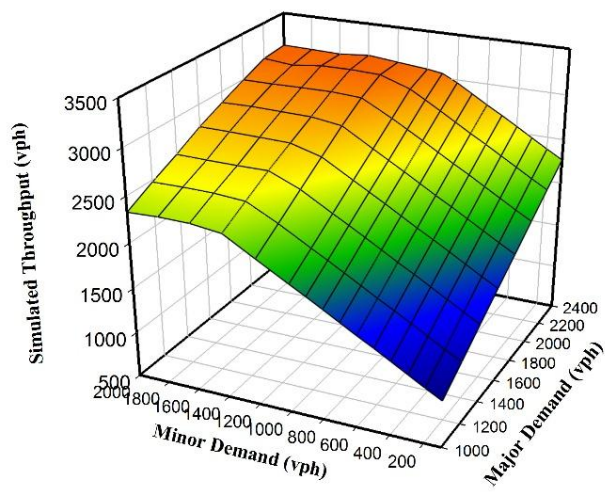

25\% Mi THR

500
1000
1500
2000 35000

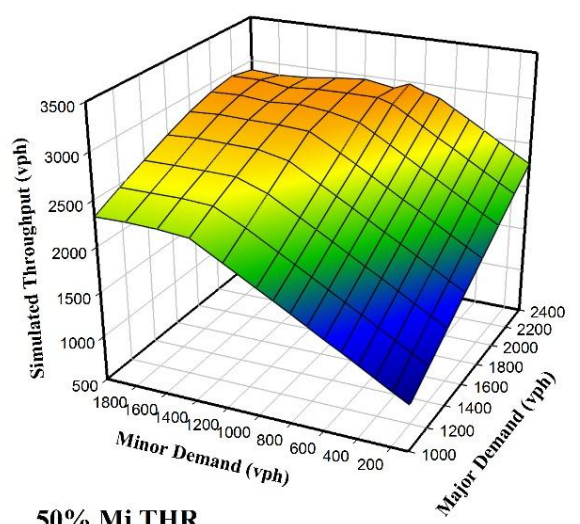

$50 \% \mathrm{Mi}$ THR

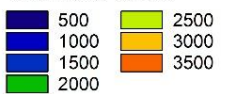

b. Simulated throughput of weaving section $(A)$ at $W L=200 m$

Formatted: Space After: 0 pt

Formatted: Tab stops: Not at 82.5 $\mathrm{mm}+165.1 \mathrm{~mm}$ 


Formatted: Font: $8 \mathrm{pt}$, Not Bold
Formatted: Font: $8 \mathrm{pt}$, Not Bold

Formatted: Font: Times New Roman, 10 pt, Bold, Font color: Black

Formatted: Font color: Black Formatted: Font: Times New Roman, 10 pt, Bold, Font color: Black

Formatted: Font: 10 pt, Bold, Font color: Black

Formatted: Font: Times New Roman, 10 pt, Bold, Font color: Black

Formatted: Font: Times New Roman

Formatted: Font: 10 pt, Font color: Black

Formatted: Font: Times New Roman, 11 pt, Font color: Black, Complex Script Font: 9 pt

Formatted: Font: Bold, Font color: Black, Do not check spelling or grammar
A MICROSIMULATION APPROACH TO EVALUATE OPERATIONS OF WEAVING SECTIONS AT URBAN UNCONV INTERSECTIONS IN CAIRO

Soliman, A.K. and Abo Hashema, M.A.Soliman, A.K. and Abo Hashema, M.A.

1

Figure 556: Relationship between total demand and throughput of weaving section (A). at different weaving lengths

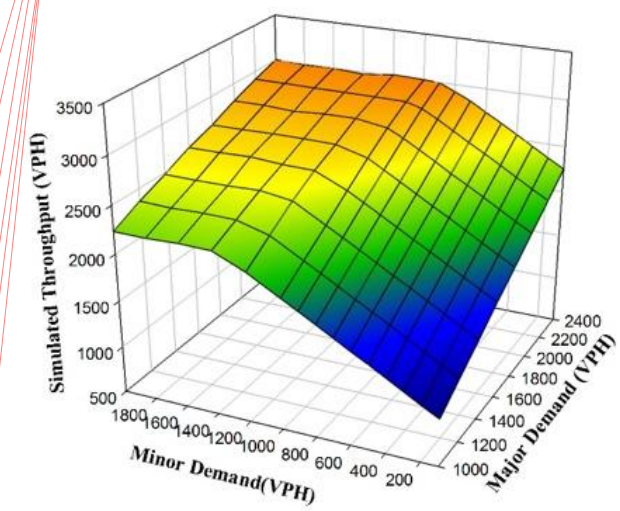

\section{$25 \%$ Mi THR}

500
1000
1500
2000 $\begin{aligned} & 2500 \\ & \square 3000 \\ & 3500\end{aligned}$

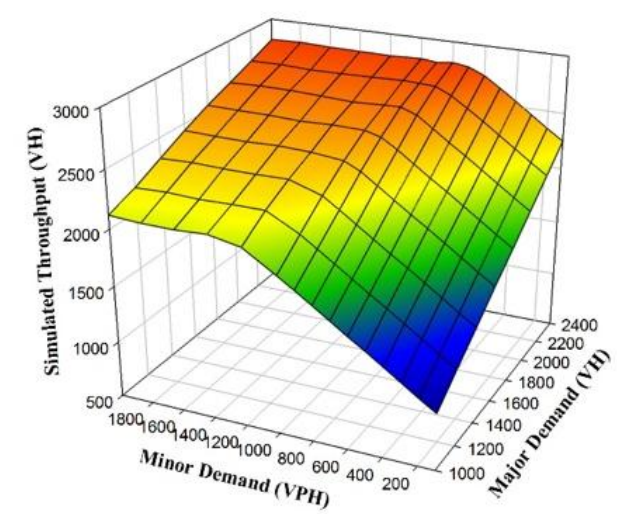

$50 \%$ Mi THR

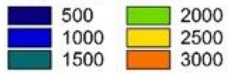

a. Simulated throughput of weaving section $(A)$ at $W L=100 \mathrm{~m}$

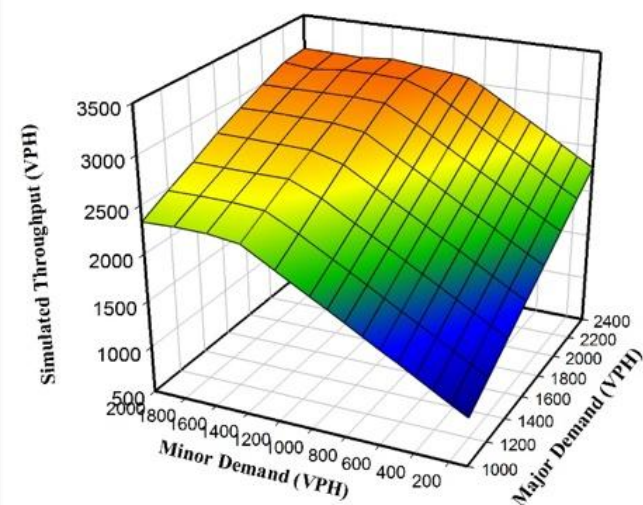

$25 \%$ Mi THR

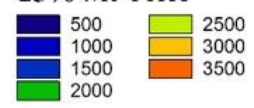

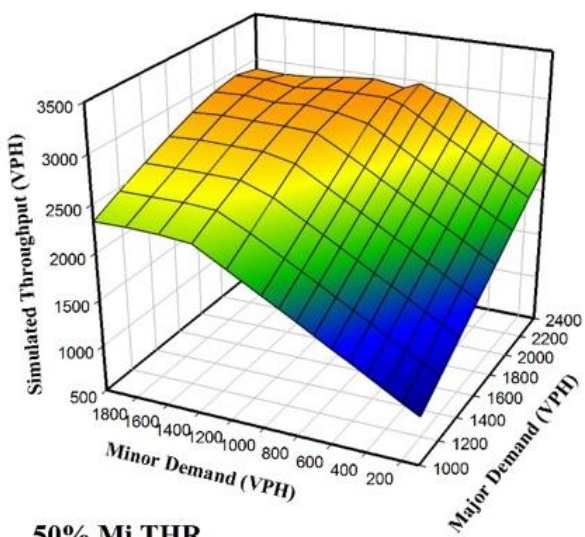

$50 \%$ Mi THR

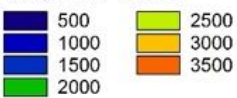

b. Simulated throughput of weaving section (A) at $W L=200 \mathrm{~m}$

Formatted: Tab stops: Not at 82.5 $\mathrm{mm}+165.1 \mathrm{~mm}$
Figure 6: Relationship between weaving section (A) demand and Throughput at different weaving lengths 
Formatted: Font: $8 \mathrm{pt}$, Not Bold Formatted: Font: $8 \mathrm{pt}$, Not Bold Formatted: Centered, After: -3.9 $\mathrm{mm}$
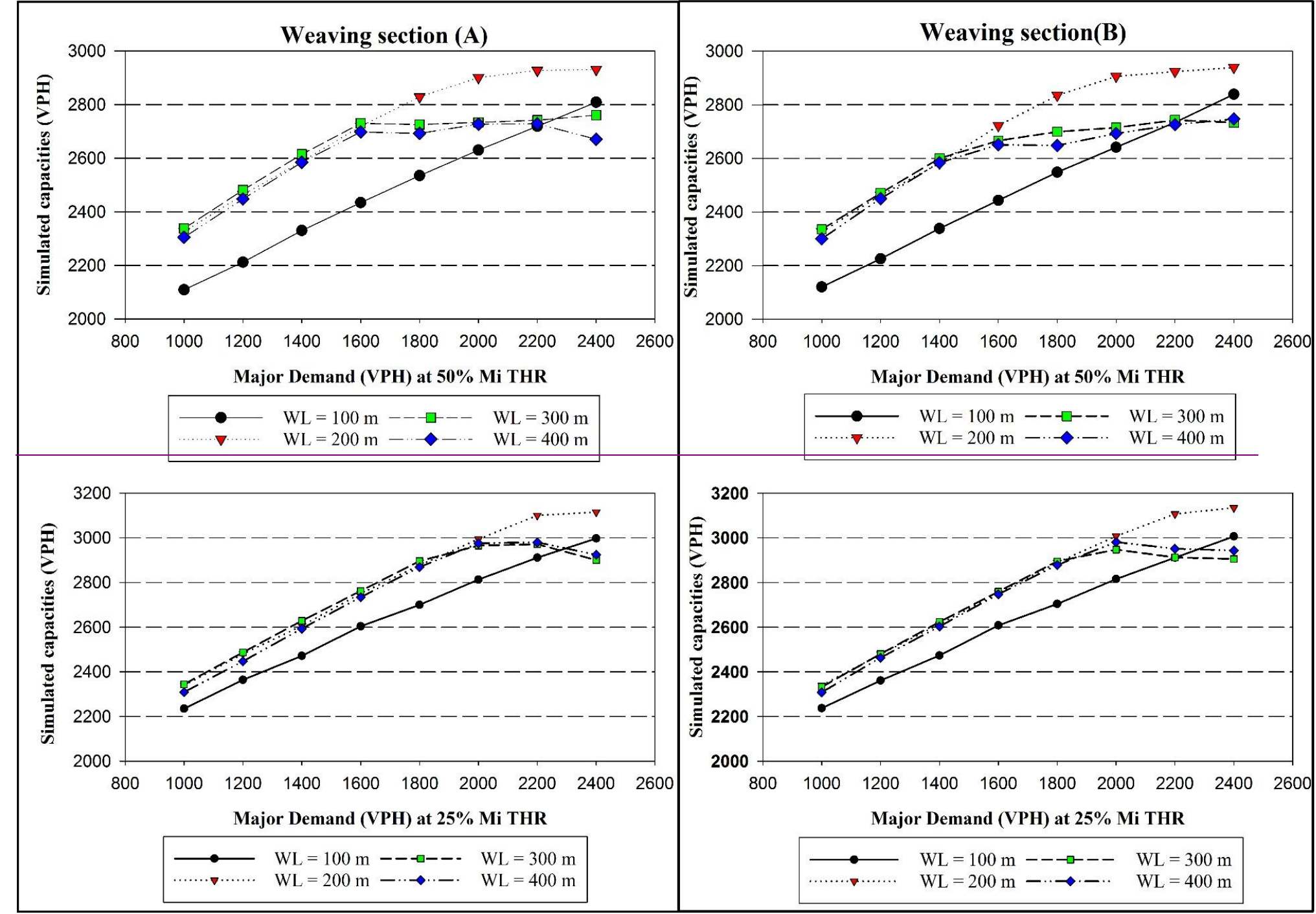
Formatted: Font: 8 pt, Not Bold Formatted: Font: 8 pt, Not Bold Formatted: Font: Times New Roman

Formatted: Font: Times New Roman, 10 pt, Font color: Black

Formatted: Font color: Black

Formatted: Font: Times New Roman, 10 pt, Font color: Black

Formatted: Font: $10 \mathrm{pt}$, Font color: Black

Formatted: Font: Times New Roman, 10 pt, Font color: Black

Formatted: Font: 10 pt, Font color: Black

Formatted: Font: Times New Roman, 10 pt, Font color: Black

Formatted: Font: Times New

Roman, Bold, Font color: Black

Formatted: Tab stops: Not at 82.5 $\mathrm{mm}+165.1 \mathrm{~mm}$
A MICROSIMULATION APPROACH TO EVALUATE OPERATIONS OF WEAVING SECTIONS AT URBAN UNCONVENTIONAL INTERSECTIONS IN CAIRO Soliman, A.K. and Abo-Hashema, M.A.Soliman, A.K. and Abo Hashema, M.A.

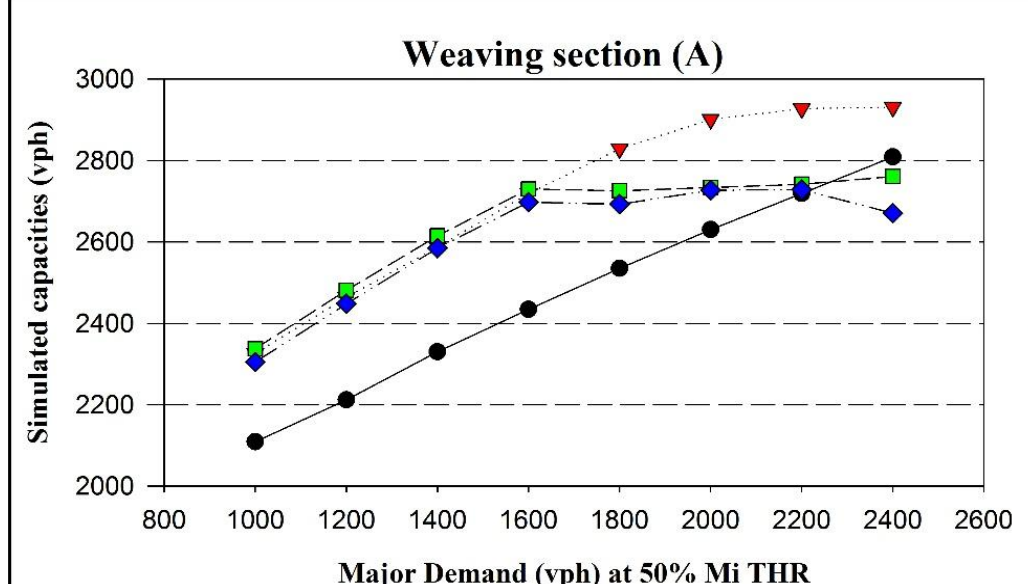

Major Demand (vph) at 50\% Mi THR
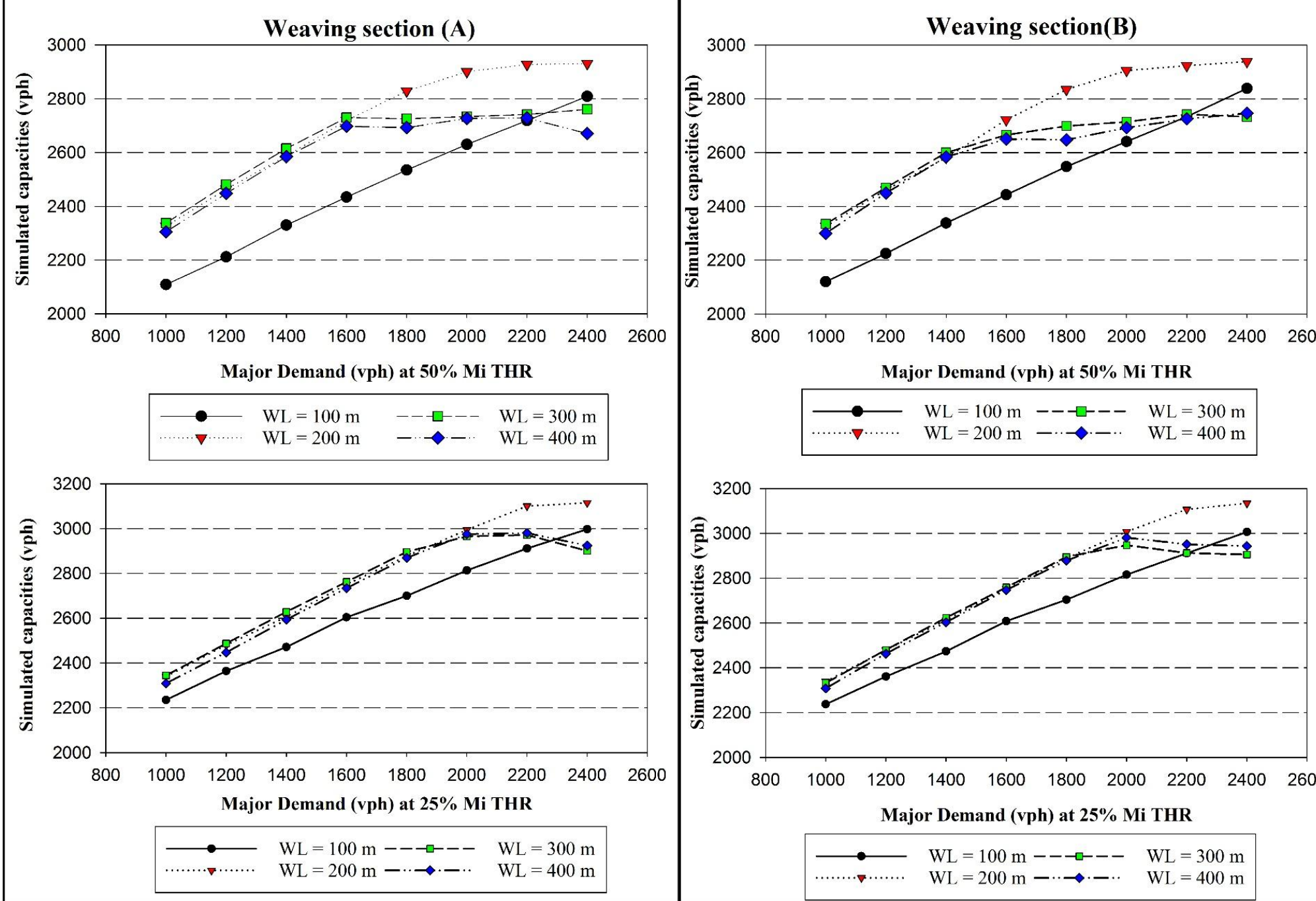

Major Demand (vph) at 50\% Mi THR

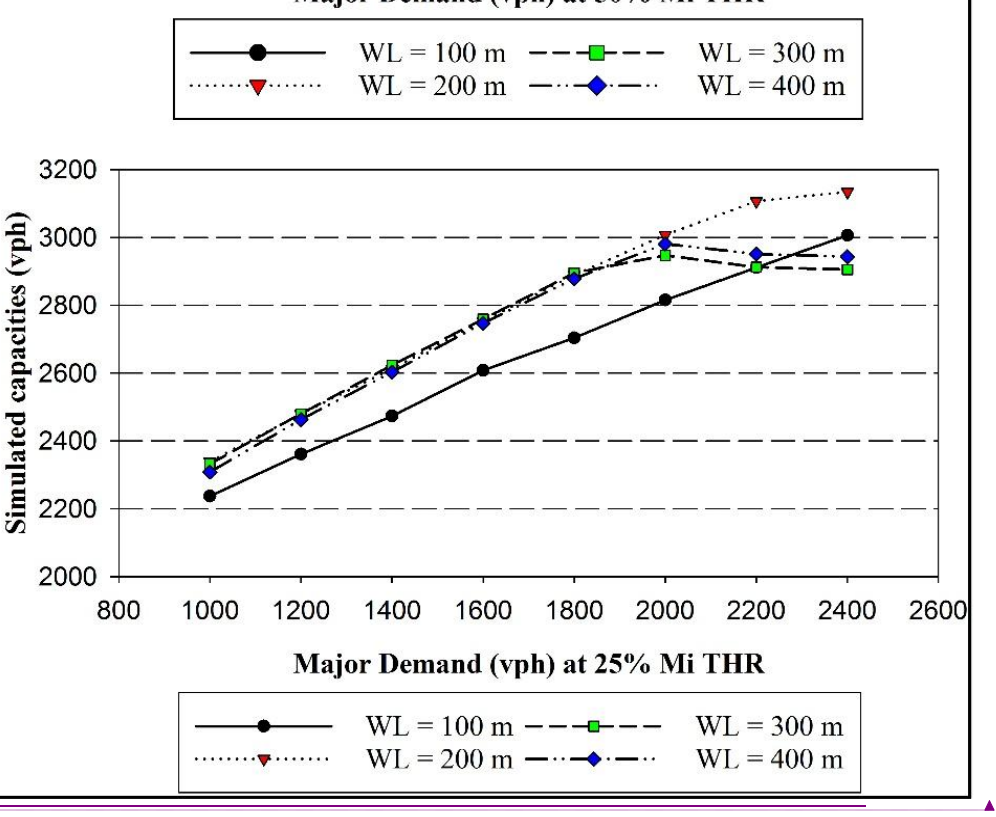

Figure 667: Simulated capacities at, different, weaving lengths 
Formatted: Font: 8 pt, Not Bold

Formatted: Font: 8 pt, Not Bold

Formatted: Left: $25.4 \mathrm{~mm}$, Right: $25.4 \mathrm{~mm}$, Width: $210 \mathrm{~mm}$, Height: $297 \mathrm{~mm}$

\section{Formatted: Centered}

Formatted: Font: Times New Roman, $10 \mathrm{pt}$

Formatted: Space Before: 0 pt, After: $0 \mathrm{pt}$

Formatted: Font: Times New

Roman, 10 pt

Formatted: Font: 10 pt, Font color: Black

Formatted: Font: 10 pt, Font color: Black

Formatted: Font: Times New Roman, 10 pt, Font color: Black

Formatted: Font color: Black

Formatted: Font: 10 pt, Font color: Black

Formatted: Font: Times New Roman, 10 pt, Font color: Black

Formatted: Font: 10 pt, Font color: Black

Formatted: Font: Times New Roman, 10 pt, Font color: Black

Formatted: Font: Times New

Roman, $10 \mathrm{pt}$

Formatted: Font: 11 pt, Font color: Auto, Complex Script Font: 11 pt

Formatted: Font: 11 pt, Font color: Auto, Complex Script Font: 11 pt

Formatted: Font: $11 \mathrm{pt}$, Font color: Auto, Complex Script Font: 11 pt

Formatted: Font: 11 pt, Font color: Auto, Complex Script Font: 11 pt

Formatted: Font: 11 pt, Font color: Auto, Complex Script Font: 11 pt

Formatted: Font: 11 pt, Font color: Auto, Complex Script Font: 11 pt

Formatted: Font: $11 \mathrm{pt}$, Font color: Auto, Complex Script Font: 11 pt

Formatted: Tab stops: Not at 82.5 $\mathrm{mm}+165.1 \mathrm{~mm}$
A MICROSIMULATION APPROACH TO EVALUATE OPERATIONS OF WEAVING SECTIONS AT URBAN UNCONV] INTERSECTIONS IN CAIRO

Soliman, A.K. and Abo Hashema, M.A.Soliman, A.K. and Abo Hashema, M.A.

4

The impact of volume ratio on capacity is summarized in figure 8 and 9. The points on ea represent the capacity at a certain major demand level.d in Figure 8. The fFigure 8 sl relationship between capacity and volume ratio for a weaving length of 100 meters as an

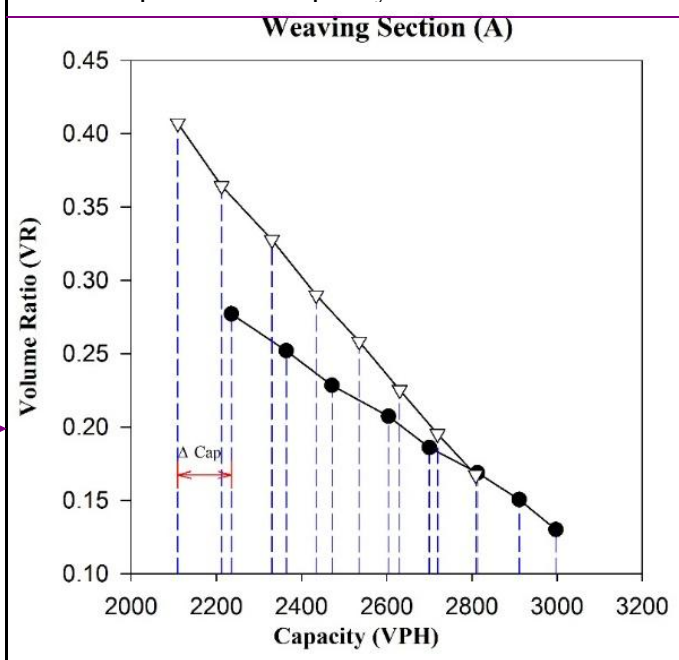

Weaving section $(B$
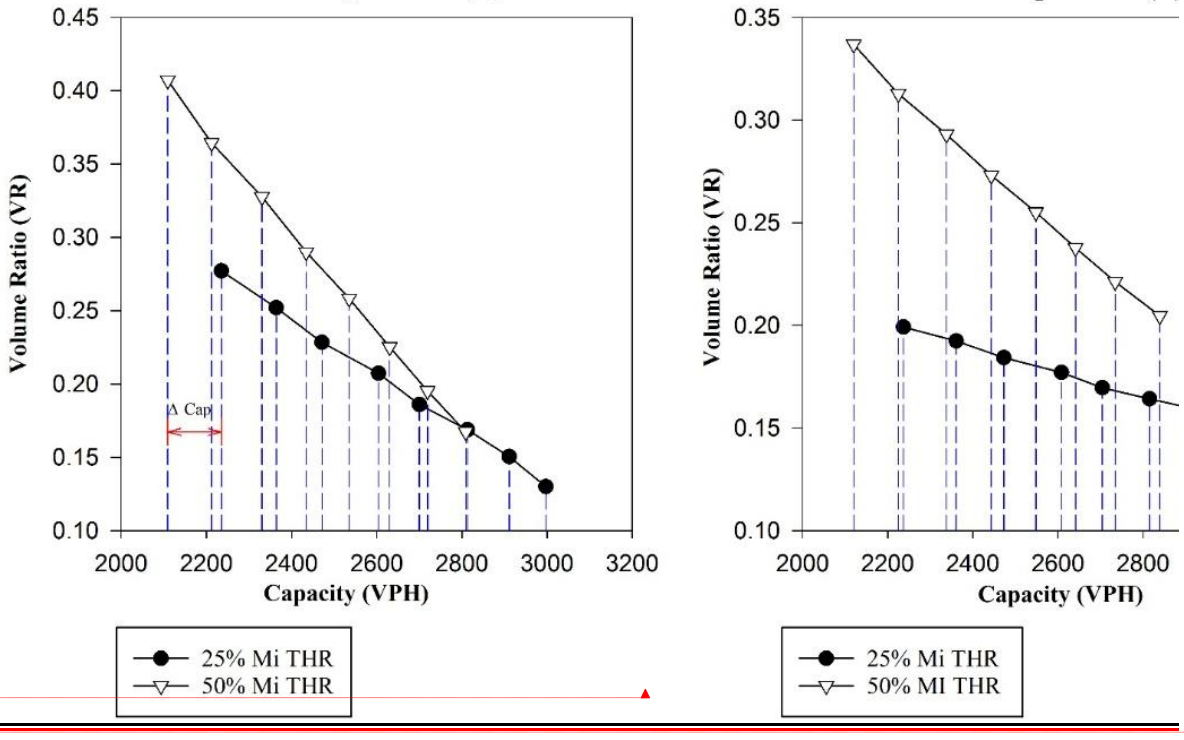

Figure, 88: eapacity Capacity versus volume ratio for WL=100,

The reduction in capacity for each pair of capacity estimates at different \% Mi THR represented by a $\Delta$ Cap on the graph. Although capacities of section $(\mathbf{A})$ and $(\mathbf{B})$ are equal ratio at capacity of weaving section $(\mathbf{B})$ is noticeably lower than its corresponding value of se for both levels of minor through traffic. This explains why sections $(\mathbf{B})$ at some points will c a relatively higher LOS than section (A) which is why it should be treated as a separate configuration.

When the weaving length was increased beyond 200 meters as shown in figure 9, capacitie increase after major demand exceeded 2000 (vph) and 1600 (vph) for $25 \%$ and $50 \%$ respectively even though volume ratio seems to be decreasing. Form figure 9 it is also notice $\triangle$ Cap associated with a major demand $<1400$ (vph) for weaving sections (A) and (B) respe minimum. Which indicates that the turbulence resulting from increasing the \% Mi THR s $25 \%$ to $50 \%$ is sustained for major demand levels $\lesseqgtr 1400$ (vph).

It is worth mentioning that when length was increased to 200 meters the simulated volu increased. However, the estimated capacities were higher than the shorter weaving sect meters) as the extra length compensates for the capacity losses due to the increase in as volu The volume ratio increases with length due to an increase in the minor entrance throughput, of weaving section (A).

When investigating the relationship between the throughput of the minor entrance, and $\mathrm{t}$ demand, it was noticed that capacities of the minor entrance have a negative correlation capacities of the weaving sections. The Capacities of the Minor entrance is inversely propo the major demand and directly proportional to the weaving length up to 200 meters. Incre length beyond 200 meters does not increase the capacity of the minor approach a in the Figure 10. 


\begin{tabular}{|l|}
\hline Formatted: Font: $8 \mathrm{pt}$, Not Bold \\
\hline Formatted: Font: $8 \mathrm{pt}$, Not Bold \\
\hline Formatted: Centered \\
\hline
\end{tabular}

Formatted: Font: (Default) Calibri, 11 pt, Font color: Black, Complex Script Font: Arial, 11 pt

Formatted: Font: (Default) Calibri, 11 pt, Font color: Black, Complex Script Font: Arial, 11 pt

Formatted: Font: (Default) Calibri, 11 pt, Font color: Black, Complex Script Font: Arial, 11 pt

Formatted: Font: (Default) Calibri, 11 pt, Font color: Black, Complex Script Font: Arial, $11 \mathrm{pt}$

Formatted: Font: (Default) Calibri, 11 pt, Font color: Black, Complex Script Font: Arial, 11 pt

Formatted: Font: 11 pt, Font color: Black

Formatted: Font: 10 pt, Bold, Font color: Black

Formatted: Centered, Space Before: 0 pt, After: 0 pt

Formatted: Font color: Black

Formatted: Font: 10 pt, Bold, Font color: Black

Formatted: Font: 10 pt, Font color: Black

Formatted: Space After: $12 \mathrm{pt}$, Line spacing: single, Don't keep with next

Formatted: Font: 11 pt, Bold, Font color: Auto, Complex Script Font: $11 \mathrm{pt}$

Formatted: Font: 11 pt, Bold, Font color: Auto, Complex Script Font: $11 \mathrm{pt}$

Formatted: Font: $11 \mathrm{pt}$

Formatted: Font: 11 pt

Formatted: Font: $11 \mathrm{pt}$, Font color: Auto, Complex Script Font: 11 pt

\begin{tabular}{|l|l|}
\hline$\ldots$ rmatted \\
\hline$\ldots$ rmatted \\
$\ldots$... rmatted
\end{tabular}

A MICROSIMULATION APPROACH TO EVALUATE OPERATIONS OF WEAVING SECTIONS AT URBAN UNCONV] INTERSECTIONS IN CAIRO

Soliman, A.K. and Abo Hashema, M.A.Soliman, A.K. and Abo Hashema, M.A. $\rightarrow$

Capacity of the weaving sections increases with the decrease in volume ratio for both cases through split. The reduction in capacity for each pair of capacity estimates at different \% Mi is represented by a $\triangle$ Cap on the graph. Although capacities of section $(A)$ and $(B)$ are equal, ratio at capacity of weaving section $(B)$ is noticeably lower than its corresponding value of st for both levels of minor through traffic. This explains why sections (B) at some points will of a relatively higher LOS than section (A).
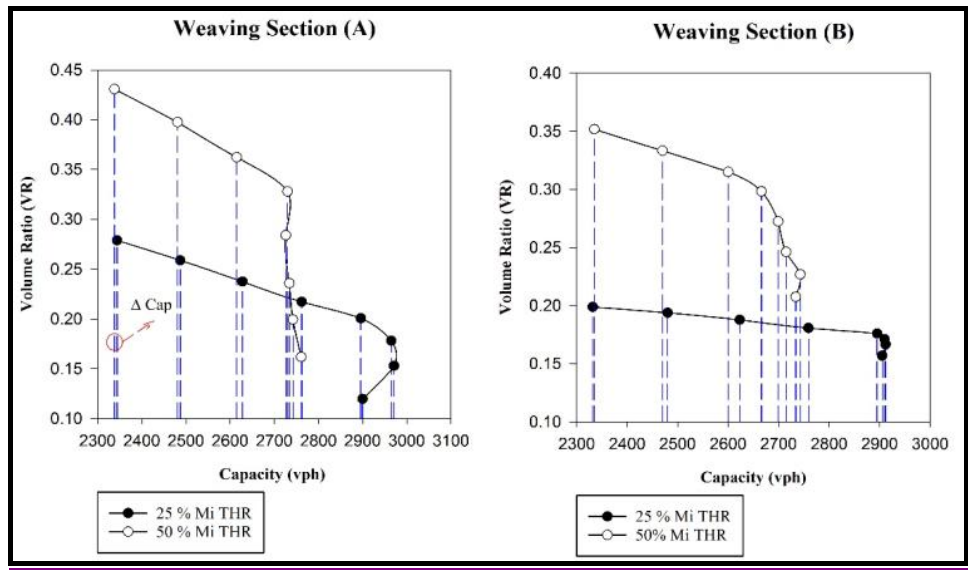

When the weavir

was increased beyond $200 \mathrm{~m}$, capacities did not increase after major demand exceeded $200 \mathrm{C}$ and 1600 (VPH) for $25 \%$ and $50 \% \mathrm{Mi}$ THR respectively even though volume ratio seems decreasing as shown in figure 9 .

\section{Figure 889: eCapacity versus volume ratio for $\mathrm{WL}=300$.}

- Form the same figure it is also noticeable that $\triangle$ Cap is associated with a major demand. (VPH) for weaving sections (A) and (B) respectively is minimum. Which indicates that the tu resulting from increasing the Mi THR split from $25 \%$ to $50 \%$ is sustained for major demand 1400 VPH. After major demand exceeds these values decrease in capacities is noticed how decrease is not more than $8 \%$ for both weaving sections.

It is worth mentioning that when length was increased to $200 \mathrm{~m}$ the simulated volume ratios $i$ however, the estimated capacities were higher than the shorter weaving section $(100 \mathrm{~m})$ as $t]$ length compensates for capacity losses due to the increase in weaving intensity as volume increases.

The volume ratio increases with length as a consequence of an increase in minor throughput-1 of weaving section (A). When investigating the relationship between the throughput of the entrance and miner demand it was noticed that capacities of the minor entrance have a nes 


\section{Formatted: Font: 8 pt, Not Bold \\ Formatted: Font: 8 pt, Not Bold}

Formatted: Font: Times New Roman

Formatted: Font: Times New Roman

Formatted: Tab stops: Not at 82.5 $\mathrm{mm}+165.1 \mathrm{~mm}$
A MICROSIMULATION APPROACH TO EVALUATE OPERATIONS OF WEAVING SECTIONS AT URBAN UNCONV] INTERSECTIONS IN CAIRO

Soliman, A.K. and Abo Hashema, M.A.Soliman, A.K. and Abo-Hashema, M.A

correlation with the capacities of the weaving sections. The Capacities of the Minor entra inversely proportional to the major demand and directly proportional to the weaving length $u$ meters. Increasing the length beyond 200 meters does not increase the capacity of the minor; as shown in the Figure 10.
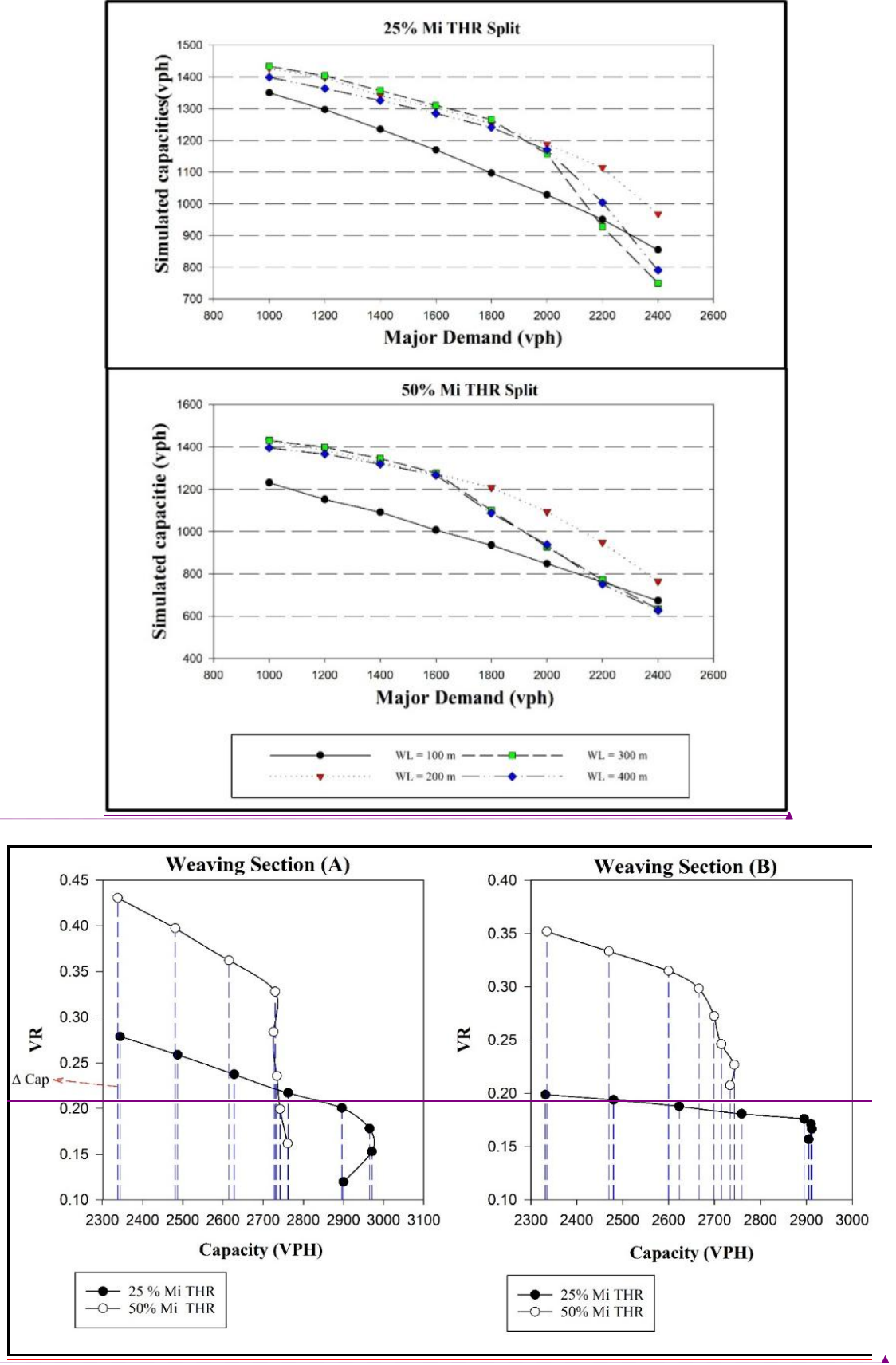


Formatted: Font: 8 pt, Not Bold
Formatted: Font: 8 pt, Not Bold
$\begin{aligned} & \text { Formatted: Font: } 10 \text { pt, Font color: } \\ & \text { Black }\end{aligned}$

Formatted: Centered, Space After: 0 pt, Line spacing: Exactly $12 \mathrm{pt}$

Formatted: Font color: Black

Formatted: Font: Times New Roman, 10 pt, Font color: Black

Formatted: Font: Times New Roman, 10 pt, Bold, Font color: Black

Formatted: Font color: Black

Formatted: Font: Times New Roman, 10 pt, Bold, Font color: Black

Formatted: Font: Times New Roman, 10 pt

Formatted: Font: Times New Roman, 10 pt, Bold, Font color: Black

Formatted: Font: $10 \mathrm{pt}$, Bold, Font color: Black

Formatted: Font: (Default) Calibri, 11 pt, Complex Script Font: Italic

Formatted: Normal, Left, Space After: 0 pt, Line spacing: single

Formatted: Centered, Space After: 0 pt, Line spacing: Exactly $12 \mathrm{pt}$
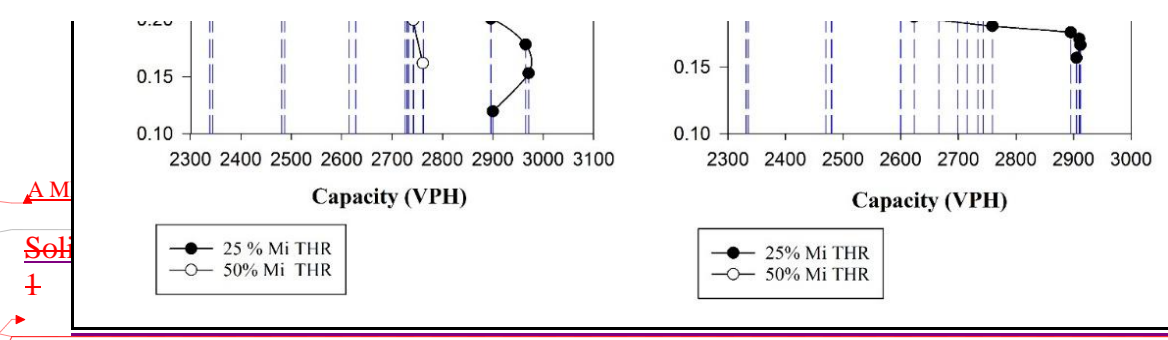

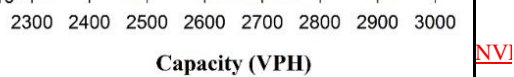

eapacity versus volume ratio for $\mathrm{WL}=300_{\mathrm{A}}$

Figure 991010: Minor entrance capacities at all levels of major demand and at different weaving lengths 


\begin{tabular}{|c|}
\hline ... rmatted \\
\hline ... rmatted \\
\hline ... rmatted \\
\hline ... rmatted \\
\hline ... rmatted \\
\hline ... rmatted \\
\hline ... rmatted \\
\hline ... rmatted \\
\hline ... rmatted \\
\hline ... rmatted \\
\hline ... rmatted \\
\hline ... rmatted \\
\hline ... rmatted \\
\hline ... rmatted \\
\hline ... rmatted \\
\hline ... rmatted \\
\hline ... rmatted \\
\hline ... rmatted \\
\hline ... ld Code Changed \\
\hline ... rmatted \\
\hline ... rmatted \\
\hline ... ld Code Changed \\
\hline ... rmatted \\
\hline ... rmatted \\
\hline ... rmatted \\
\hline ... rmatted \\
\hline ... rmatted \\
\hline ... rmatted \\
\hline ... rmatted \\
\hline ... rmatted \\
\hline ... rmatted \\
\hline ... rmatted \\
\hline ... rmatted \\
\hline ... rmatted \\
\hline ... rmatted \\
\hline ... rmatted \\
\hline ... rmatted \\
\hline ... rmatted \\
\hline ... rmatted \\
\hline ... rmatted \\
\hline ... rmatted \\
\hline ... rmatted \\
\hline ... rmatted \\
\hline
\end{tabular}

A MICROSIMULATION APPROACH TO EVALUATE OPERATIONS OF WEAVING SECTIONS AT URBAN UNCONV] INTERSECTIONS IN CAIRO

Soliman, A.K. and Abo Hashema, M.A.Soliman, A.K. and Abo Hashema, M.A. 4

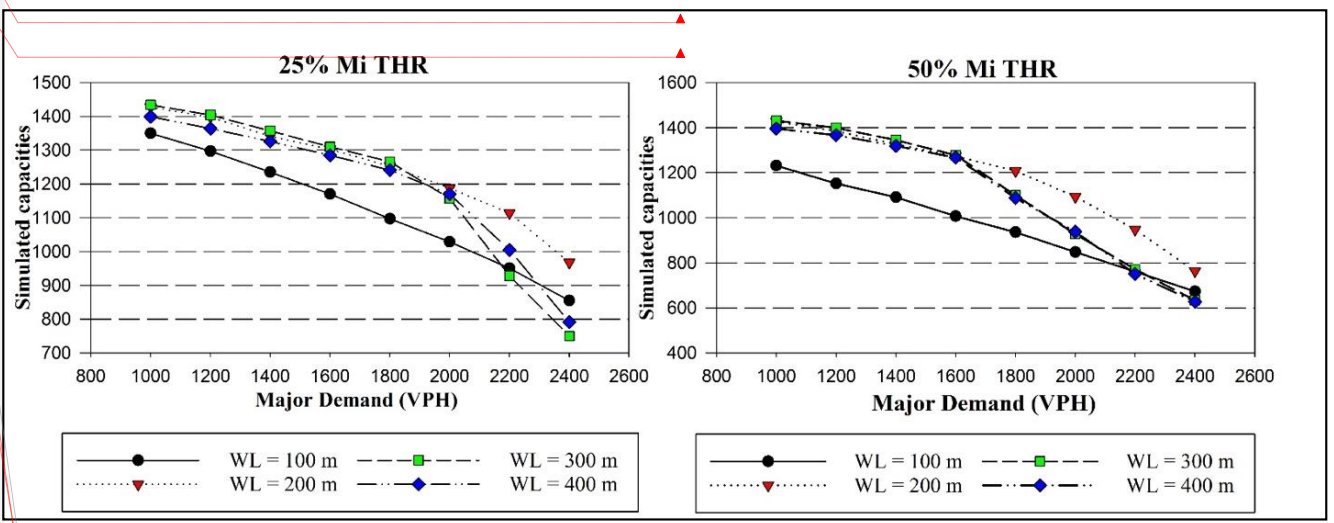

5.2 simulationSimulation based capacity prediction models

Simulation based Capacity prediction models were developed to predict the capacity of section (A) and and (B)-for a specific length. These models; however, are limited to a weaving length and the range of data used to develop the modelsmodels. In addition, the $\mathrm{m}$ constrained to the assumptions made for the study network.. IncreasingIncreasing the weavi] beyond 200 meters was not beneficial as illustrated andbefore, and they are not recomme field implementation-therefore no models were developed for these lengths.

LinearLinear and non-linear regression procedures provided by the Statistical analysis softw: was-were utilized to develop two capacity prediction models as illustrated below.shown belor

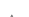

For WL of $100 \mathrm{~m}$ the following models were developed: $\rightarrow \quad$ Model 1111: logarithmic Logarithmic Capacity Prediction Model For section (A): $\mathrm{CAP}=875.184172 * \ln (\mathrm{MD})-1.287523 * \mathrm{VR} * \mathrm{MD}-3433.603297$

For Section (B): $\mathrm{CAP}=\mathbf{1 0 5 3 . 6 5} * \ln (\mathrm{MD})-\mathbf{1 . 0 6}$ * VR $* \mathrm{MD}-\mathbf{4 8 4 6 . 6 7}$

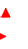

$\rightarrow$ For section (A):

Model 2222: Linear Capacity Prediction Model

For Section (B):

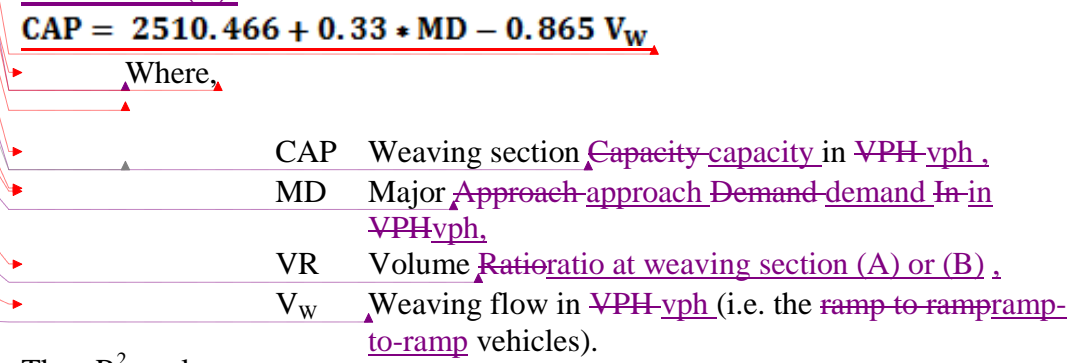

The $\mathrm{R}^{2}$ values 


\section{Formatted: Font: 8 pt, Not Bold \\ Formatted: Font: 8 pt, Not Bold}

Formatted: Font: $11 \mathrm{pt}$

rmatted

Formatted: No underline

rmatted

Formatted: Font: 4 pt, Bold

rmatted

Formatted: Space After: 0 pt

rmatted

Formatted: Font: Bold

... rmatted

Field Code Changed

Field Code Changed

rmatted

rmatted

rmatted

... rmatted

Formatted: Font: Bold

rmatted

rmatted

Field Code Changed

rmatted

rmatted

Field Code Changed

\begin{tabular}{|c|}
\hline rmatted \\
\hline rmatted \\
\hline rmatted \\
\hline rmatted \\
\hline rmatted \\
\hline rmatted \\
\hline rmatted \\
\hline rmatted \\
\hline rmatted \\
\hline rmatted \\
\hline rmatted \\
\hline rmatted \\
\hline
\end{tabular}

A MICROSIMULATION APPROACH TO EVALUATE OPERATIONS OF WEAVING SECTIONS AT URBAN UNCONV] INTERSECTIONS IN CAIRO

Soliman, A.K. and Abo Hashema, M.A.Soliman, A.K. and Abo-Hashema, M.A

4

logarithmic models is are relatively high (0.992) which indicates a perfect fit. The negative the coefficient of volume ratio is also logical which means that when volume ratio is incr capacity decreases. The $\mathrm{R}^{2}$ value of the linear models are 2 is -also high, $(0.975)$ anc respectively. and aAll coefficient signs are also relevant indicating logical correlation bet dependant variable and the predictors.

For WL of $200 \mathrm{~m}$ the following models were developed:

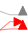

For section (A):

Model 3333: logarithmicLogarithmic Capacity Prediction Model

$\mathrm{CAP}=866.13925 .075 * \ln (\mathrm{MD})-0.298-0.312 * \mathrm{VR} * \mathrm{MD}-3538.473956 .661$

For section $(B):$ CAP $=949.27 * \ln (M D)-0.42 * V R * M D-4111.98$

$\mathrm{CAP}=925.075 * \ln (\mathrm{MD})-0.312 * \mathrm{VR} * \mathrm{MD}-3956.661$

Model 4444: Linear capacity prediction model

$\rightarrow$ For section (A):

$\mathrm{CAP}=1977.41+0.495 * \mathrm{MD}-0.1 \mathrm{~V}_{\mathrm{W}} \mathrm{CAP}=1912.324+0.556 * \mathrm{MD}-0.129 \mathrm{~V}_{\mathrm{W}}$

$\rightarrow$ For section (B):

$\mathrm{CAP}=1968.56+0.52 * \mathrm{MD}-0.16 \mathrm{~V}_{\mathrm{W}} \mathrm{CAP}=1912.324+0.556 * \mathrm{MD}-0.129 \mathrm{~V}_{\mathrm{W}}$

$\rightarrow$ The $\mathrm{R}^{2}$ values for of the logarithmic models is-equal (=-0.983961) and (0.968) which is 1 high while the linear model has a $\mathrm{R}^{2}$ respectively, which is relatively high, while the linea have an $\mathrm{R}^{2}$, values ef of $(0.969929)$ and $(0.932)$ whichrespectively. All models coefficien relevant signs.

$\rightarrow$ is also high. All models have relevant signs indicating logical correlation between the depent variable and the predictors.

\section{3 applicabilityAPPLICABILITY OF hem-HCM 2010 WEAVING ANALYSIS} METHODOLOGY

$\rightarrow$ To facilitate the application of HCM, an excel based calculation sheet is-was developed to the operational measures of weaving section (A) and (B) using the simulated weaving weaving volumes obtained from 960 simulation runs. All the algorithms embedded in the $c \varepsilon$ sheet is explained-found in the HCM 2010 chapter 12 [1].

-5.3.1 capacity Capacity

$\rightarrow$ The HCM 2010 presents a straight forwardstraightforward equation to estimate the lane ca the weaving section whichsection, which in this case will be a two--sided weaving sectiol make comparisons possible some adjustments were made to the capacity values derived 1 HCM 2010 to be more compatible with the capacities estimated using VISSIM. These adjustı as following:

- Simulated capacities are provided for the entire section therefore, HCM capac multiplied by the number of lanes $\mathrm{N}=3$.

- Simulated capacities are were given obtained in VPH $\underline{v p h}$ therefor,therefor; HCM c should be adjusted to $\mathrm{VPH}$ vph using the heaving vehicle factor FHV.

- Weaving Length should be in units of feat.

The following equation is used to estimate the capacity of the weaving section in HCM 2010: 


\section{Formatted: Font: 8 pt, Not Bold \\ Formatted: Font: 8 pt, Not Bold}

Formatted: Font color: Auto

Formatted: Indent: Before: 6.3 $\mathrm{mm}$, First line: $5.1 \mathrm{~mm}$, Space After: $0 \mathrm{pt}$

\section{Field Code Changed}

Formatted: Font color: Auto

Formatted: Font: 11 pt, Not Bold,

Font color: Auto, Complex Script

Font: $11 \mathrm{pt}$

Formatted: Font: $11 \mathrm{pt}$, Not Bold

Formatted: Font color: Red

Formatted: Line spacing: single

Formatted: Font: 11 pt, Not Bold,

Font color: Black, Complex Script Font: $11 \mathrm{pt}$

Formatted: Centered, Line spacing: single

Formatted: Font: 11 pt, Not Bold, Complex Script Font: 11 pt Subscript

Formatted: Font: 11 pt, Not Bold, Font color: Black, Complex Script Font: $11 \mathrm{pt}$

Formatted: Font: 11 pt, Not Bold, Font color: Black, Complex Script Font: $11 \mathrm{pt}$

Formatted: Font: 11 pt, Not Bold, Font color: Black, Complex Script

Font: $11 \mathrm{pt}$

\begin{tabular}{|l|l|}
\hline$\ldots$ & rmatted \\
\hline$\ldots$ & rmatted \\
\hline Formatted: Font: $11 \mathrm{pt}$ \\
\hline$\ldots$ & rmatted \\
\hline$\ldots$ & rmatted \\
\hline Formatted \\
\hline Formatted: Space After: $0 \mathrm{pt}$ \\
\hline$\ldots$ rmatted \\
\hline$\ldots$ rmatted \\
\hline$\ldots$ rmatted \\
\hline$\ldots$ rmatted \\
\hline
\end{tabular}

A MICROSIMULATION APPROACH TO EVALUATE OPERATIONS OF WEAVING SECTIONS AT URBAN UNCONV] INTERSECTIONS IN CAIRO

Soliman, A.K. and Abo Hashema, M.A.Seliman, A.K. and Abo-Hashema, M.A

4

\section{$\rightarrow \quad C_{I W L}=C_{I F L}-\left[438.2(1+V R)^{1.6}\right]+\left[0.0765 L_{S}\right]+\left[119.8 N_{W L}\right]$}

capacity of the weaving segment under equivalent ideal conditions, $\quad$ Where, per lane (pc/h/ln),

capacity of a basic freeway segment with the same FFS as the weaving

segment under equivalent ideal conditions, per lane ( $\mathrm{pc} / \mathrm{h} / \mathrm{ln})$

volume ratio, $v_{\underline{W}} / \underline{v}$,

length of the weaving segment $(\mathrm{ft})$,

number of lanes from which a weaving maneuver may be made with one or

no lane changes ( for two-sided weaving section $\mathrm{N}_{\mathrm{WL}}=0$ )

$\rightarrow$ The comparison is established for the urban weaving sections studied in this research, i.e.,i.e. of lanes is 3 lanes -, configuration is a two-sided weaving section, number of weaving lanes $z_{0}$ and FFS $=60 \mathrm{~km} / \mathrm{h}(37.5 \mathrm{mph})$. No base capacity was established for speeds less than 55 HCM 2010 therefore, base capacity per lane was assumed $1800 \mathrm{vph}$. -Factor of heavy vehicl calculated using the mythology methodology provided in chapter 11 of the-_HCM 2010 [1]. I heavy vehicle factor could be ignored $_{2}$ as $2 \%$ heavy vehicles is an-insignificant. valuf .

The following fFigure 11 shows a comparisonthe relationship between the simulated capaci the capacities predicted using the developed models and the HCM 2010 model-capacity me
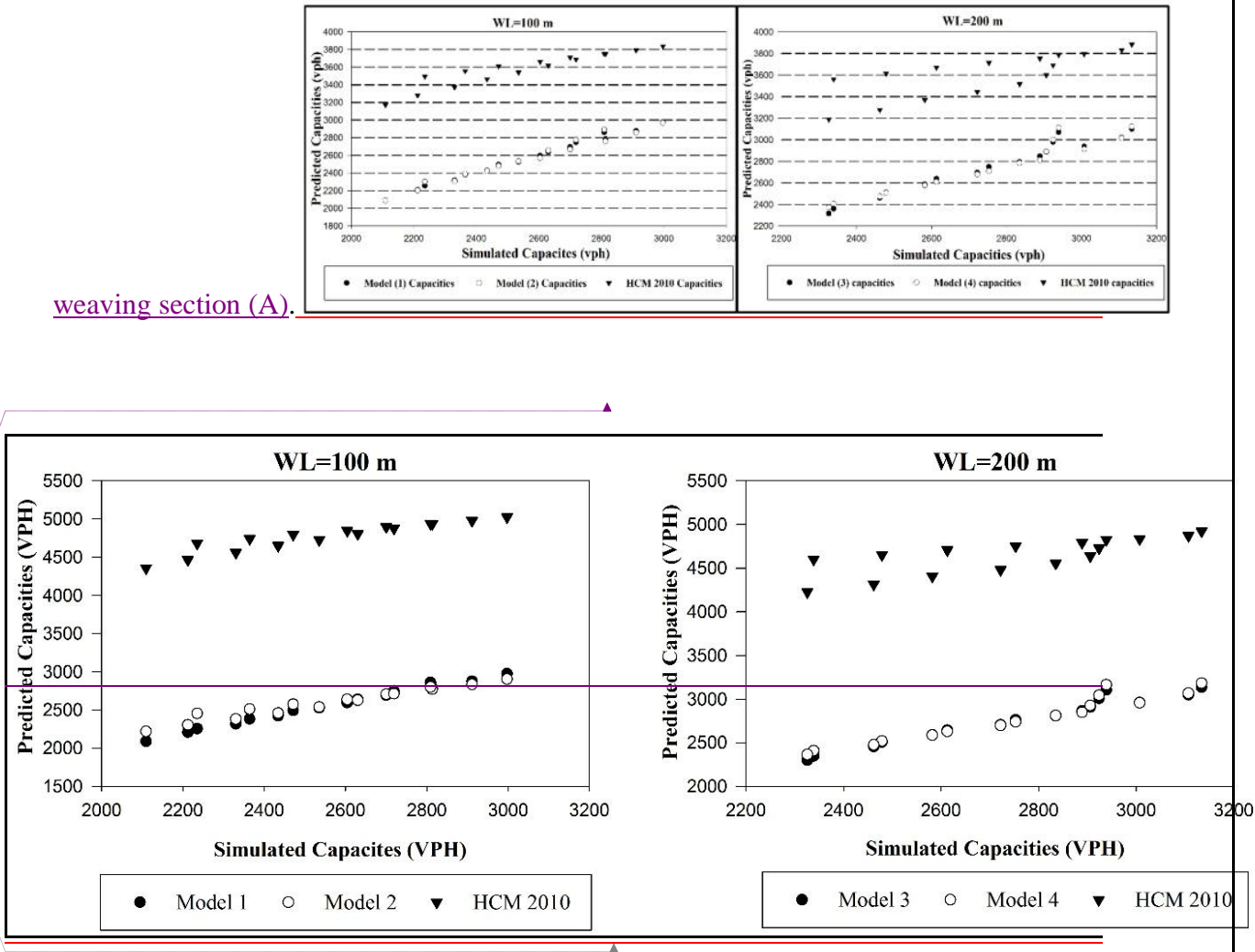

$\rightarrow \quad$ Figure 10101111: Predicted versus simulated capacities, using HCM2010 and the develop models for weaving section (A)

It is evident that the HCM model over predicts capacities and should not be used for simi configurations. Capacities predicted by HCM are at some points more than double the s 
Formatted: Font: $8 \mathrm{pt}$, Not Bold

Formatted: Font: 8 pt, Not Bold

Formatted: Space Before: 0 pt, After: 0 pt, Line spacing: Exactly $12 \mathrm{pt}$

Formatted: Font: Times New Roman, 11 pt, Font color: Red Complex Script Font: 11 pt

Formatted: Font: Times New Roman, 11 pt, Font color: Red, Complex Script Font: 11 pt, Superscript

Formatted: Font: Times New Roman, 11 pt, Font color: Red, Complex Script Font: 11 pt

Formatted: Font: 11 pt, Underline, Font color: Auto, Complex Script Font: $11 \mathrm{pt}$

Formatted: Font: Bold, Underline

Formatted: Font color: Auto, Subscript

Formatted: Font color: Auto, Subscript

Formatted: Font color: Auto, Subscript

Formatted: Font: Not Bold, Font color: Auto

Formatted: Left

Formatted: Font: Not Bold

rmatted

rmatted

... rmatted

rmatted

rmatted

rmatted

rmatted

rmatted

rmatted

rmatted

rmatted

rmatted

Formatted: Font color: Black

rmatted

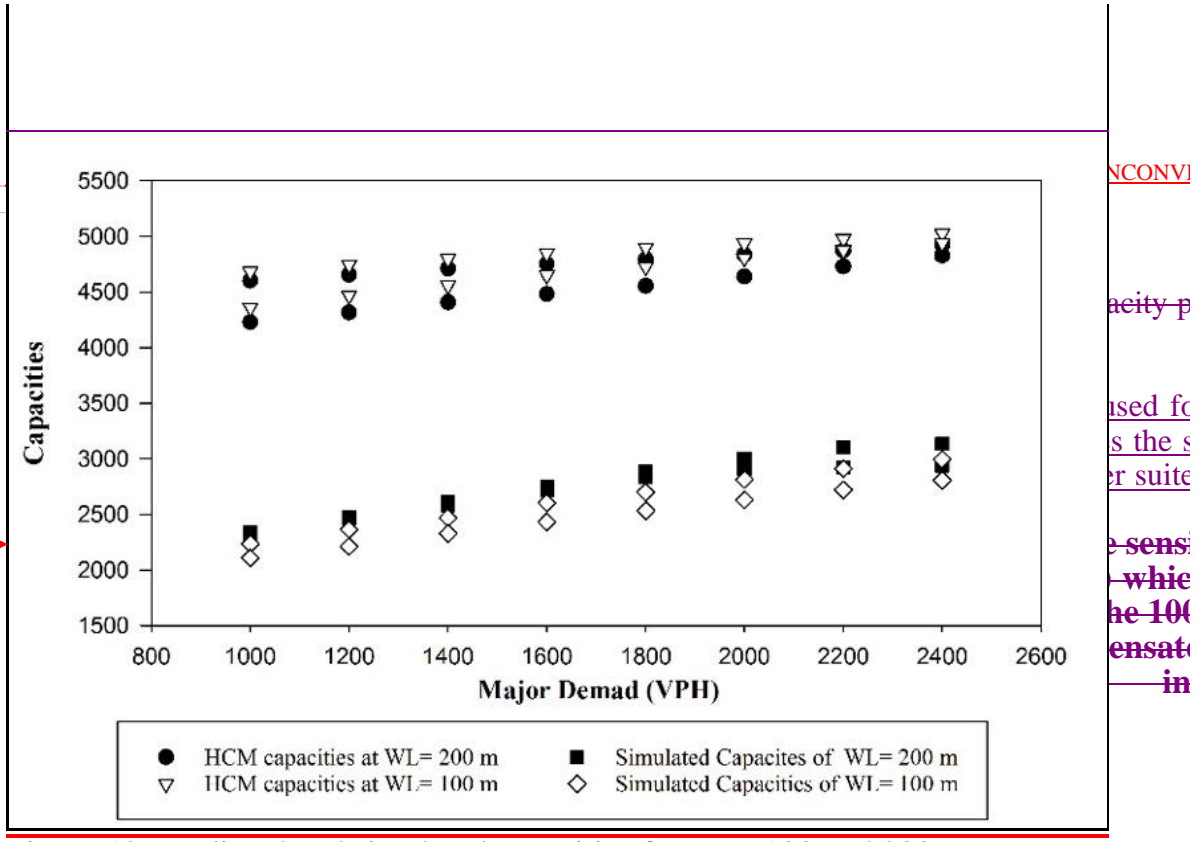

Figure 12: predicted and simulated capacities for $\mathrm{WL}=100$ and $200 \mathrm{~m}$

Attempts to calibrate the HCM model structure to fit the simulated capacities using non regression yielded very low $R^{2}$-values indieating that the modelstructure itself is not suil this type of urban weaving section and the develop model structure clearly is better and suitable for this type of weaving section.

\subsection{2 laneLane change rates}

The speed prediction models of the HCM 2010 mainly depends on the rate of lane changes $v$ weaving section of study. The total lane-changing rate of all vehicles in the weaving $\mathrm{s}$ computed by combining weaving lane change rates and non-weaving lane change.

The model for predicting weaving lane changing rate in HCM 2010 is as following:

$$
\underline{\mathbf{L} C_{M I N}=L_{R R} \times \mathbf{V}_{\mathrm{W}}}
$$

$\rightarrow$ Where,

$$
\underline{L C}_{\underline{W}}=\underline{L} \underline{L}_{M I N}+0.39\left[\left(L_{S}-300\right)^{0.5} \mathrm{~N}^{2}(1+\mathrm{ID})^{0.8}\right]
$$

$\underline{\mathrm{LC}}_{\text {MIN }}$ Minimum equivalent hourly rate weaving vehicles must make to successfully complete all weaving maneuvers

$\underline{L_{C}} \underline{\text { Minimum number of lane changes that must be made by one ramp to ramp }}$ vehicle to execute the desired maneuver successfully

$\underline{\mathrm{V}}_{\mathrm{W}} \quad$ Weaving volume in $\mathrm{pc} / \mathrm{h}$

$\underline{\mathrm{LC}_{\mathrm{W}}} \quad$ Equivalent hourly rate at which weaving vehicles make lane changes within the weaving section $(\mathrm{Lc} / \mathrm{h})$

$\mathrm{L}_{\mathrm{S}} \quad$ Length of the weaving section (ft);

N Number of lanes within the weaving section;

ID Interchange density.

- For the urban two-sided weaving sections studied in this research $L_{R_{R}}=2$, and ID is $\underline{0.67}$.

The model for predicting non-weaving lane changing rate in HCM 2010 is as following:

- First, a non-weaving vehicle index, " $\mathrm{NW}_{2}$ needs to be calculated and then depending of the non-weaving lane changing rates are calculated using one of the three non-wear change rate equations below. 


\begin{tabular}{|c|}
\hline ... rmatted \\
\hline ... rmatted \\
\hline ... rmatted \\
\hline ... rmatted \\
\hline ... rmatted \\
\hline ... rmatted \\
\hline ... rmatted \\
\hline ... rmatted \\
\hline ... rmatted \\
\hline ... rmatted \\
\hline ... rmatted \\
\hline ... rmatted \\
\hline ... rmatted \\
\hline ... rmatted \\
\hline ... rmatted \\
\hline ... rmatted \\
\hline ... rmatted \\
\hline ... rmatted \\
\hline ... rmatted \\
\hline ... rmatted \\
\hline ... rmatted \\
\hline ... rmatted \\
\hline ... rmatted \\
\hline ... rmatted \\
\hline ... rmatted \\
\hline ... rmatted \\
\hline ... rmatted \\
\hline ... rmatted \\
\hline ... rmatted \\
\hline ... rmatted \\
\hline ... rmatted \\
\hline ... rmatted \\
\hline ... rmatted \\
\hline ... rmatted \\
\hline ... rmatted \\
\hline ... rmatted \\
\hline ... rmatted \\
\hline ... rmatted \\
\hline ... rmatted \\
\hline ... rmatted \\
\hline ... rmatted \\
\hline ... rmatted \\
\hline ... rmatted \\
\hline
\end{tabular}

A MICROSIMULATION APPROACH TO EVALUATE OPERATIONS OF WEAVING SECTIONS AT URBAN UNCONV INTERSECTIONS IN CAIRO

Soliman, A.K. and Abo Hashema, M.A.Seliman, A.K. and Abo Hashema, M.A $\mathrm{f}_{\mathrm{NW}}=\frac{\mathrm{L}_{\mathrm{S}} * \mathrm{ID} * \mathrm{~V}_{\mathrm{NW}}}{10000}$

\begin{tabular}{|c|c|c|c|}
\hline & If $\mathbf{I}_{\mathrm{NW}} \leqq 1300$ & then & $\mathrm{LC}_{\mathrm{NW}}=\mathrm{LC}_{\mathrm{NW} 1}$ \\
\hline & If $\mathbf{I}_{\mathrm{NW}} \geqq 1950$ & then & $\mathrm{LC}_{\mathrm{NW}}=\mathrm{LC}_{\mathrm{NW} 2}$ \\
\hline & If $1300<$ I $_{\mathrm{NW}_{L}}<1950$ & then & $\mathrm{LC}_{\mathrm{NW}}=\mathrm{LC}_{\mathrm{NW} 3}$ \\
\hline$\rightarrow$ & \multicolumn{3}{|c|}{$\frac{L C_{N W 1}=\left(0.206 * V_{N W}\right)+\left(0.542 * L_{S}\right)-(192.6 * N)}{L C_{N W 2}=2,135+0.223\left(V_{N W}-2,000\right)}$} \\
\hline$\rightarrow$ & $\mathrm{LC}_{\mathrm{NW3}}$ & (1) -I & $\left.\mathrm{Nw1}_{1}\right) *\left((\mathbf{1} / \mathbf{6 5 0})\left(\mathrm{I}_{\mathrm{NW}}-\mathbf{1 3 0 0 ) )}\right.\right.$ \\
\hline
\end{tabular}

The total lane-changing rate of all vehicles in the weaving section is then computed by cr $\underline{\mathrm{LC}_{\mathrm{W}}}$ and $\mathrm{LC}_{\mathrm{NW}}$.

$$
\underline{\underline{L}} \underline{A L L}=\underline{\mathrm{LC}} \underline{\underline{\mathrm{W}}}+\underline{\underline{\mathrm{LC}}} \underline{\underline{N W}}
$$

In VISSIM, lane change evaluations were set to calculate the total number of lane changes that occurs at each weaving section. Paired t-tests were executed using SPSS statistical packa the null hypothesis whichhypothesis, which states that there is no significant difference bet simulated and the predicted lane changes at section $(\mathbf{A})$ and $(\mathbf{B})$ for each weaving length.

Parity plots of the simulated versus predicted estimates were also generated, which gives description of the relationship between the ebserved-simulated and the predicted values. $\mathrm{T}$ the plot of points to the $45^{\circ}$ Line, the more accurate the predicted speeds. If points are on t] the $45^{\circ}$ Line, predicted lane changes are generally larger while predicted lane changes are values on the right of the line.

Parity plots are shown in figure 12 for weaving length of 100 and 200_asmeters as an ex Figure 13. By examining the plots, it is evident that there is a moderate to high magnitude degree ofa high positive correlation between the predicted and the simulated values. Clearly the points are to the right of -the $45_{-}^{\circ}$-degree line whichline, which indicates that the simul change rate is higher than the predicted. The same analogy can be applied on the rest of the lengths in this study.

The following table shows the result of paired t-test with a significance value $<0.05$ indic: there is a statistically significant difference between the simulated and the predicted valuess: the predicted values, and thereby rejecting the null hypothesis.

\begin{tabular}{|c|c|c|c|c|c|c|c|c|c|c|c|}
\hline & & & & & Paired & Differ & nces & & $\mathbf{t}$ & df & \\
\hline$\frac{\frac{\mathscr{v}}{\tilde{E}}}{\underline{\underline{E}}}$ & . & 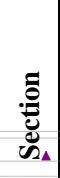 & Lane change rates & Mean & $\begin{array}{c}\text { Std. } \\
\text { Deviation }\end{array}$ & 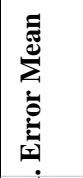 & $\begin{array}{r}95 \\
\text { Confi } \\
\text { Interva } \\
\text { Diffe }\end{array}$ & $\begin{array}{l}\% \\
\text { lence } \\
\text { of the } \\
\text { ence }\end{array}$ & & & $\mid$ \\
\hline & & & & & & $\bar{n}_{A}$ & Lower & Upper & & & \\
\hline Pair 1 & 8 & A & $\begin{array}{c}\text { Simulated_LC - } \\
\text { HCM_LC }\end{array}$ & 63.64 & 257.64 & 16.63 & 30.87 & 96.40 & 3.83 & 239.00 & .00 \\
\hline Pair 2 & & B & $\begin{array}{c}\text { Simulated_LC - } \\
\text { HCM_LC }\end{array}$ & 130.71 & 137.49 & 8.87 & 113.22 & 148.19 & 14.73 & 239.00 & .00 \\
\hline Pair 3 & 8 & A & $\begin{array}{c}\text { Simulated_LC - } \\
\text { HCM_LC }\end{array}$ & 396.49 & 317.66 & 20.50 & 356.09 & 436.88 & 19.34 & 239.00 & .00 \\
\hline Pair 4 & त) & B & $\begin{array}{c}\text { Simulated_LC - } \\
\text { HCM_LC }\end{array}$ & 821.62 & 326.68 & 21.09 & 780.08 & 863.16 & 38.96 & 239.00 & .00 \\
\hline Pair 5 & $\underset{ల}{8}$ & A & $\begin{array}{c}\text { Simulated_LC - } \\
\text { HCM_LC }\end{array}$ & 490.53 & 389.40 & 25.14 & 441.01 & 540.04 & 19.51 & 239.00 & .00 \\
\hline
\end{tabular}




\section{Formatted: Font: 8 pt, Not Bold \\ Formatted: Font: 8 pt, Not Bold}

Formatted: Font: 10 pt, Font color Auto

Formatted: Font color: Auto

Formatted: Font: $10 \mathrm{pt}$, Font color: Auto

Formatted: Font: $10 \mathrm{pt}$

Formatted: Font: $10 \mathrm{pt}$

Formatted: Font: 1 pt

Formatted: Font: 11 pt
A MICROSIMULATION APPROACH TO EVALUATE OPERATIONS OF WEAVING SECTIONS AT URBAN UNCONV] INTERSECTIONS IN CAIRO

Soliman, A.K. and Abo Hashema, M.A.Soliman, A.K. and Abo Hashema, M.A. 4

\begin{tabular}{|c|c|c|c|c|c|c|c|c|c|c|c|}
\hline Pair 6 & & B & $\begin{array}{c}\text { Simulated_LC - } \\
\text { HCM_LC }\end{array}$ & 646.39 & 391.31 & 25.26 & 596.63 & 696.15 & 25.59 & 239.00 & .00 \\
\hline Pair 7 & 0 & A & $\begin{array}{c}\text { Simulated_LC - } \\
\text { HCM_LC }\end{array}$ & 352.22 & 411.38 & 26.55 & 299.91 & 404.53 & 13.26 & 239.00 & .00 \\
\hline Pair 8 & \% & B & $\begin{array}{c}\text { Simulated_LC - } \\
\text { HCM_LC }\end{array}$ & 524.27 & 430.23 & 27.77 & 469.57 & 578.98 & 18.88 & 239.00 & .00 \\
\hline
\end{tabular}

Table 222: Lane change rates Paired Samples Test

From the previous sectionsection, it was concluded that the lane change prediction models by HCM 2010 clearly under-predicts the rate of lane changes for this type of urban weaving Consequently, the predicted speeds are likely to be higher than the actual speeds. 
Formatted: Font: 8 pt, Not Bold Formatted: Font: 8 pt, Not Bold
A MICROSIMULATION APPROACH TO EVALUATE OPERATIONS OF WEAVING SECTIONS AT URBAN UNCONV] INTERSECTIONS IN CAIRO

Soliman, A.K. and Abo Hashema, M.A.Soliman, A.K. and Abo Hashema, M.A.

Formatted: Tab stops: Not at 82.5 $\mathrm{mm}+165.1 \mathrm{~mm}$ 


\begin{tabular}{|l|}
\hline Formatted: Font: 8 pt, Not Bold \\
\hline Formatted: Font: 8 pt, Not Bold \\
\hline
\end{tabular}

Formatted: Font: Times New Roman, 10 pt, Bold, Font color: Black

Formatted: Font: Times New Roman, 10 pt, Bold, Font color: Black

Formatted: Font color: Black Formatted: Font: Times New Roman, 10 pt, Bold, Font color: Black

Formatted: Font: $10 \mathrm{pt}$, Font color: Black

Formatted: Font: Times New Roman, 10 pt, Bold, Font color: Black

Formatted: Font: $10 \mathrm{pt}$, Font color: Black

Formatted: Font: Times New Roman, 10 pt, Bold, Font color: Black

Formatted: Font: Times New Roman, $10 \mathrm{pt}$

Formatted: Tab stops: Not at 82.5 $\mathrm{mm}+165.1 \mathrm{~mm}$
A MICROSIMULATION APPROACH TO EVALUATE OPERATIONS OF WEAVING SECTIONS AT URBAN UNCONV] INTERSECTIONS IN CAIRO

Soliman, A.K. and Abo Hashema, M.A.Soliman, A.K. and Abo Hashema, M.A. 4
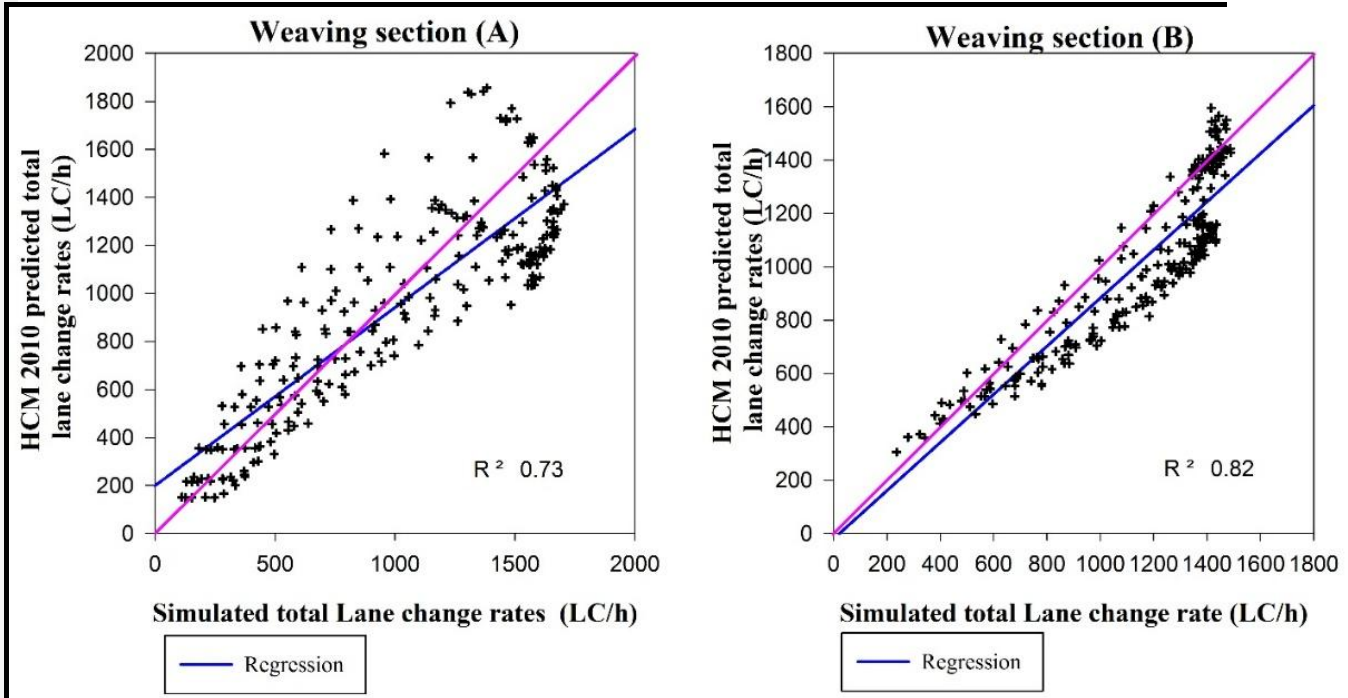

a. HCM 2010 Predicted total lane change rates versus Simulated total lane change rates for WL=100 m
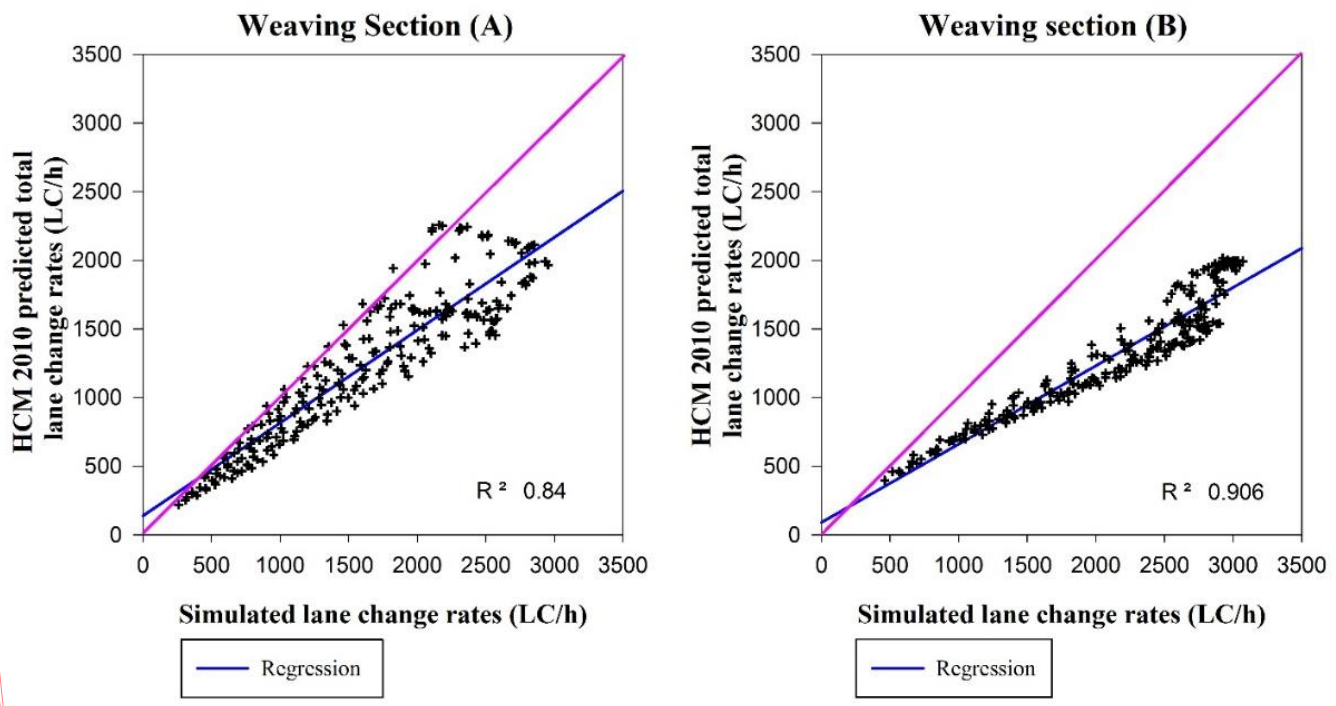

b. HCM 2010 Predicted total lane change rates versus Simulated total lane change rates for $W L=200 \mathrm{~m}$

Figure-Fig. 11111213: Parity plots for of the simulated verses predicted lane change rate for $W L=100$ and 200 meters 


\begin{tabular}{|c|}
\hline Formatted: Font: $8 \mathrm{pt}$, Not Bold \\
\hline Formatted: Font: 8 pt, Not Bold \\
\hline $\begin{array}{l}\text { Formatted: Font: (Default) Calibri, } \\
\text { Not Bold }\end{array}$ \\
\hline $\begin{array}{l}\text { Formatted: Space Before: } 6 \mathrm{pt} \text {, } \\
\text { Line spacing: single }\end{array}$ \\
\hline Formatted: Space After: $0 \mathrm{pt}$ \\
\hline ... rmatted \\
\hline ... Id Code Changed \\
\hline ... rmatted \\
\hline Field Code Changed \\
\hline ... rmatted \\
\hline ... rmatted \\
\hline ... rmatted \\
\hline ... rmatted \\
\hline ... rmatted \\
\hline ... rmatted \\
\hline ... rmatted \\
\hline ... rmatted \\
\hline ... rmatted \\
\hline ... rmatted \\
\hline ... rmatted \\
\hline ... rmatted \\
\hline ... rmatted \\
\hline ... rmatted \\
\hline ... rmatted \\
\hline ... rmatted \\
\hline ... rmatted \\
\hline ... rmatted \\
\hline ... rmatted \\
\hline ... rmatted \\
\hline ... rmatted \\
\hline ... rmatted \\
\hline ... rmatted \\
\hline ... rmatted \\
\hline Formatted: Font: $11 \mathrm{pt}$ \\
\hline ... rmatted \\
\hline Formatted: Font: $11 \mathrm{pt}$ \\
\hline ... rmatted \\
\hline
\end{tabular}

A MICROSIMULATION APPROACH TO EVALUATE OPERATIONS OF WEAVING SECTIONS AT URBAN UNCONV] INTERSECTIONS IN CAIRO

Soliman, A.K. and Abo Hashema, M.A.Soliman, A.K. and Abo Hashema, M.A.

1

$\longrightarrow$

\subsection{3 weavingWeaving and non-weaving speed $\left(\mathrm{s}_{\mathrm{w}}, \mathrm{s}_{\mathrm{nw}}\right)$}

$\rightarrow$ The HCM 2010 presented two models for the prediction of weaving and non-weaving speer models and dependant on the rate of lane changes where speeds would decrease with increas changing activity - a real measure of weaving intensity. It is worth mentioning that the prec non-weaving vehicle speed is the weakest part of the HCM 2010 methodology [6].

$$
\begin{aligned}
& S_{W}=15+\frac{F F S-15}{1+W} \quad, \quad W=0.226 *\left(\frac{L C_{A L L}}{L_{S}}\right)^{0.789} \text { (Weaving speed prediction } \\
& S_{N W}=F F S-\left(0.0072 * L C_{M I N}\right)-\left(0.0048 * \frac{V}{N}\right)
\end{aligned}
$$

Where,

$S_{\mathrm{W}} \quad$ Average speed of weaving vehicles in (mi/h);

Snw Average speed of non-weaving vehicles in (mi/h);

$\mathrm{LC}_{\mathrm{Min}}$ Minimum lane change rate depending on geometry

$\mathrm{LC}_{\mathrm{ALL}}$ Total rate of lane changes

$\mathrm{N} \quad$ Number of lanes in the weaving section

FFS Free flow speed

$\mathrm{V} \quad$ Total flow rate in pcu

W Weaving intensity factor

$\mathrm{V}$ Total flow rate in pcu

LS Weaving length in $\mathrm{ft}$

In VISSIM, travel time sections were utilized to capture the weaving and non-weaving s1 both weaving section (A) and (B) and-The travel time definitions of weaving and non-weaving movements to maintain consistency when $\epsilon$ comparing simulated and predicted samples.

All HCM predicted weaving and non weaving s Speeds that were estimated using HC previously converted into $\mathrm{Km} / \mathrm{h}$ for consistency aswell. in the HCM 2010 calculation sheet $\mathrm{p}$ : developed for this study.

A Paired sample t-test was carried out to compare the simulated and predicted weaving weaving speeds and parity plots alsewere developed-generated for each weavin: Figurelength. Figure $14-13$ shows parity plots for weaving length of 100 and 400 met example-.

As expected the HCM models over predicted the speeds of all movements as shown in the $\mathrm{p}$ Goodness of fit $\left(\mathrm{R}^{2}\right)$ was very small and all the plotted points were on the left side of the 4 : lineline, which means that the predicted speeds are higher.-

It is also noticeable that the simulated speeds were more spread compared to that of the speeds,speeds; however, there is a significant degree of linearity and a positive correlat weaving and non- weaving speeds failed the T-test with significance value $\leq>0.05$ an concluded that the results-speeds were significantly different as shown in Table 3. 
Formatted: Font: $8 \mathrm{pt}$, Not Bold

Formatted: Font: 8 pt, Not Bold

Formatted: Font: Times New

Roman

\begin{tabular}{|l|l|}
\hline$\ldots$ & rmatted \\
\hline$\ldots$ & rmatted \\
\hline$\ldots$ & rmatted \\
\hline
\end{tabular}

Formatted: Font color: Auto

rmatted

Formatted: Font: Bold

\section{rmatted}

Formatted: Font color: Auto

Formatted: Font: Bold

Formatted: Font: Bold

Formatted: Font: Bold

Formatted: Font: Bold

Formatted: Left, Wrap Around

rmatted

Formatted: Left, Wrap Around

rmatted

Formatted: Left, Wrap Around

rmatted

Formatted: Font: Bold

Formatted: Left, Wrap Around

rmatted

Formatted: Left, Wrap Around

rmatted

Formatted: Left, Wrap Around

rmatted

Formatted: Left, Wrap Around

rmatted

Formatted: Font: Bold

Formatted: Left, Wrap Around

rmatted

Formatted: Left, Wrap Around

rmatted

Formatted: Left, Wrap Around

Formatted: Font: Bold

rmatted
A MICROSIMULATION APPROACH TO EVALUATE OPERATIONS OF WEAVING SECTIONS AT URBAN UNCONV] INTERSECTIONS IN CAIRO

Soliman, A.K. and Abo Hashema, M.A.Soliman, A.K. and Abo-Hashema, M.A

4

Table 3333: Weaving and non-weaving speeds Paired Samples Test

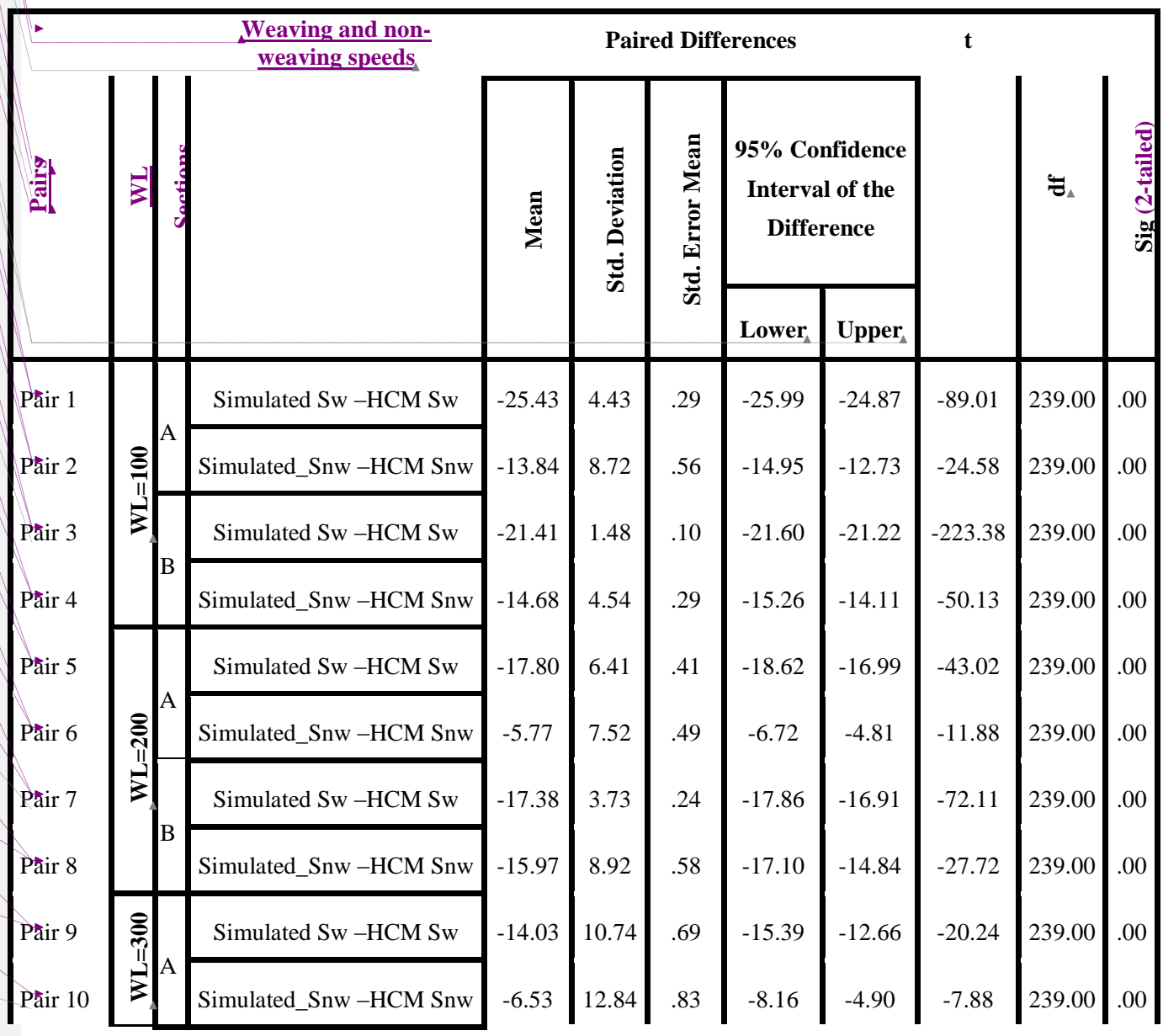




\begin{tabular}{|l|}
\hline Formatted: Font: 8 pt, Not Bold \\
\hline Formatted: Font: 8 pt, Not Bold \\
\hline Formatted: Left, Wrap Around \\
\hline $\begin{array}{l}\text { Formatted: Centered, Wrap } \\
\text { Around }\end{array}$ \\
\hline Formatted: Left, Wrap Around \\
\hline $\begin{array}{l}\text { Formatted: Centered, Wrap } \\
\text { Around }\end{array}$ \\
\hline Formatted: Left, Wrap Around \\
\hline $\begin{array}{l}\text { Formatted: Centered, Wrap } \\
\text { Around }\end{array}$ \\
\hline Formatted: Left, Wrap Around \\
\hline $\begin{array}{l}\text { Formatted: Centered, Wrap } \\
\text { Around }\end{array}$ \\
\hline Formatted: Left, Wrap Around \\
\hline $\begin{array}{l}\text { Formatted: Centered, Wrap } \\
\text { Around }\end{array}$ \\
\hline Formatted: Font: Bold \\
\hline Formatted: Left, Wrap Around \\
\hline $\begin{array}{l}\text { Formatted: Centered, Wrap } \\
\text { Around }\end{array}$ \\
\hline
\end{tabular}

\section{A MICROSIMULATION APPROACH TO EVALUATE OPERATIONS OF WEAVING SECTIONS AT URBAN UNCONV]} INTERSECTIONS IN CAIRO

\section{Soliman, A.K. and Abo Hashema, M.A.Soliman, A.K. and Abo Hashema, M.A.}

\begin{tabular}{|c|c|c|c|c|c|c|c|c|c|c|c|}
\hline Păir 11 & & \multirow{2}{*}{$B$} & Simulated Sw -HCM Sw & -27.11 & 3.75 & .24 & -27.59 & -26.63 & -112.00 & 239.00 & .00 \\
\hline Päir 12 & & & Simulated_Snw -HCM Snw & -14.80 & 11.58 & .75 & -16.28 & -13.33 & -19.80 & 239.00 & .00 \\
\hline Păir 13 & \multirow{4}{*}{ 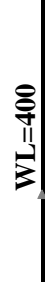 } & \multirow{2}{*}{ A } & Simulated Sw -HCM Sw & -11.48 & 11.17 & .72 & -12.90 & -10.06 & -15.91 & 239.00 & .00 \\
\hline Pair 14 & & & Simulated_Snw -HCM Snw & -4.47 & 13.04 & .84 & -6.12 & -2.81 & -5.31 & 239.00 & .00 \\
\hline Păir 15 & & \multirow{2}{*}{ B } & Simulated Sw -HCM Sw & -12.79 & 7.24 & .47 & -13.71 & -11.87 & -27.37 & 239.00 & .00 \\
\hline Pair 16 & & & Simulated_Snw -HCM Snw & -13.07 & 11.93 & .77 & -14.59 & -11.56 & -16.97 & 239.00 & .00 \\
\hline
\end{tabular}

Formatted: Tab stops: Not at 82.5 $\mathrm{mm}+165.1 \mathrm{~mm}$ 
Formatted: Font: 8 pt, Not Bold

Formatted: Font: 8 pt, Not Bold

Formatted: Font: Times New Roman
A MICROSIMULATION APPROACH TO EVALUATE OPERATIONS OF WEAVING SECTIONS AT URBAN UNCONV] INTERSECTIONS IN CAIRO

Soliman, A.K. and Abo Hashema, M.A.Soliman, A.K. and Abo Hashema, M.A
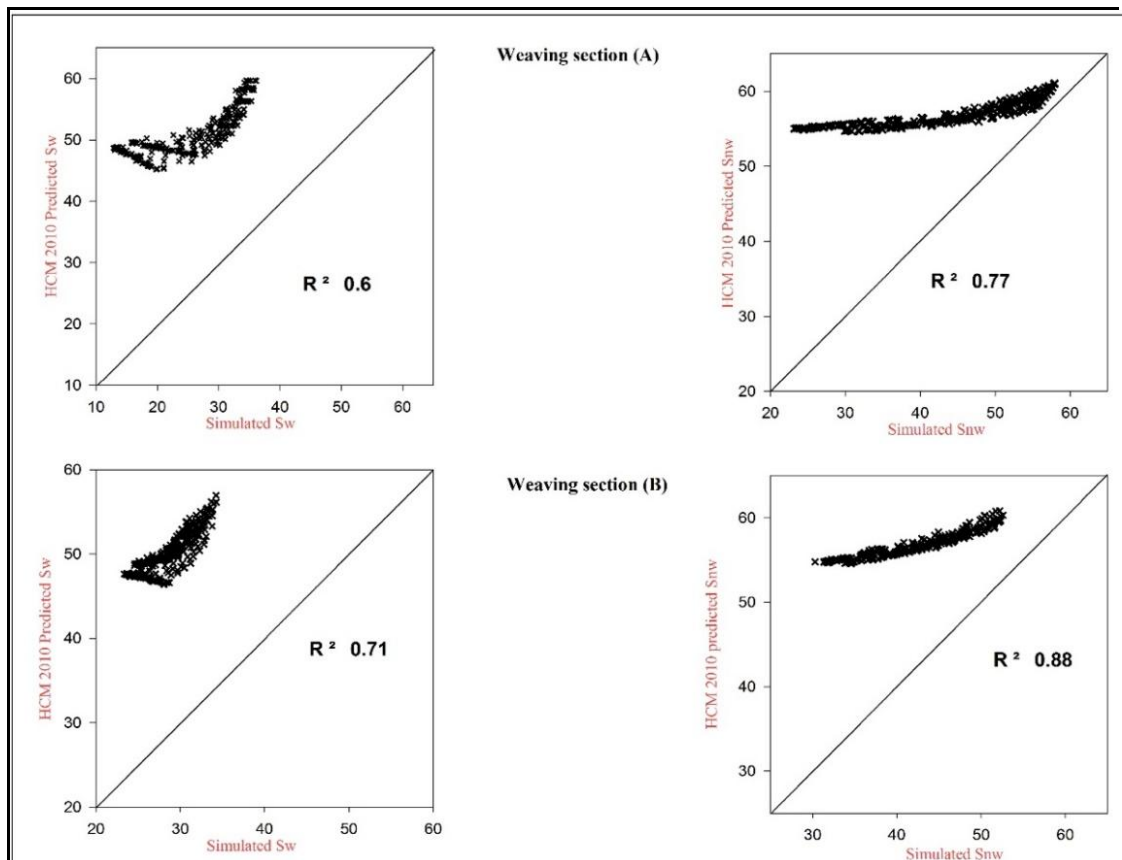

Weaving section (B)

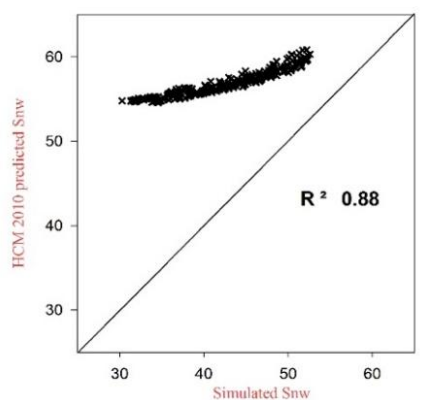
a. HCM 2010 Predicted speeds versus VISSIM simulated speeds for $W L=100 \mathrm{~m}$

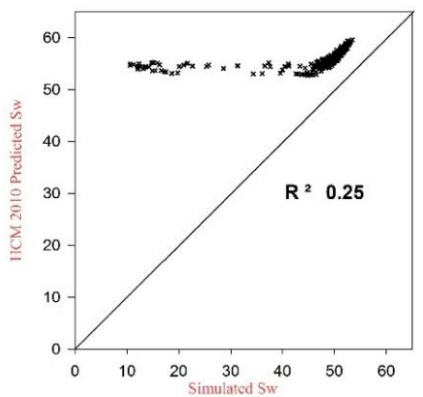

Weaving Section (A)
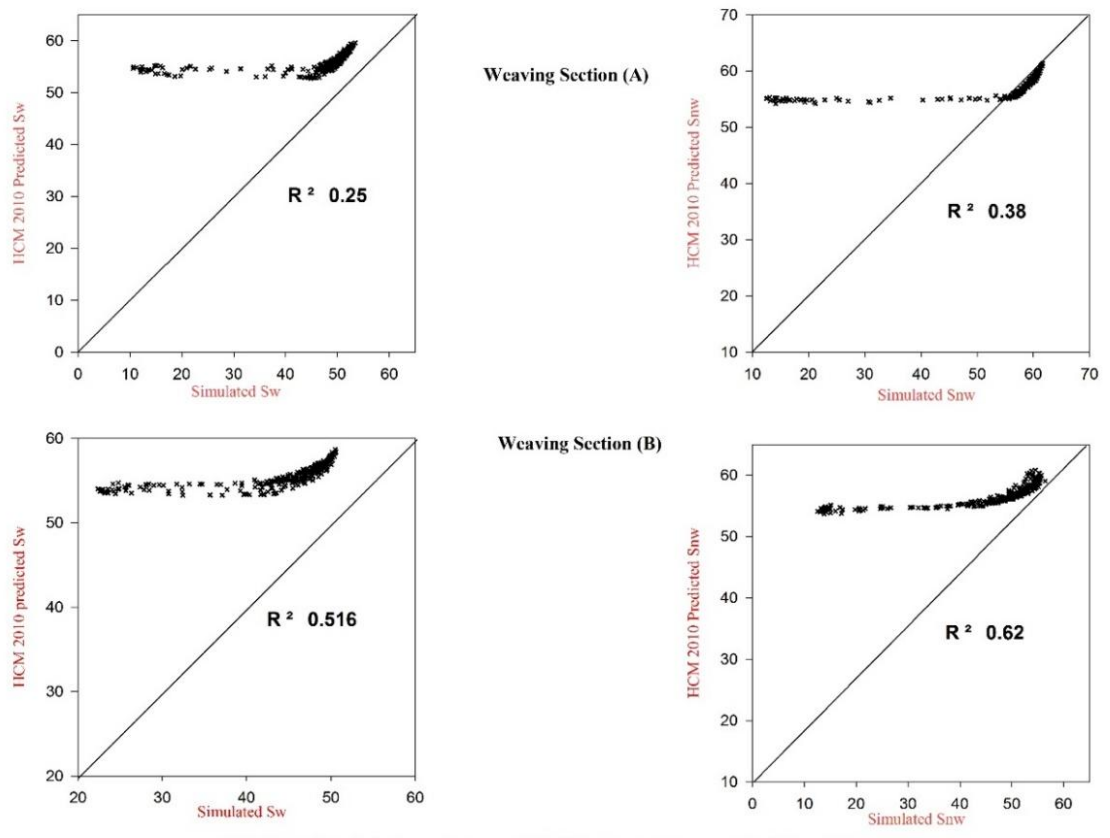

Weaving Scction (B)

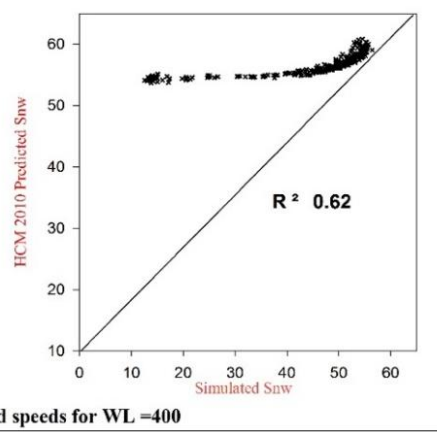




\begin{tabular}{l} 
Formatted: Font: 8 pt, Not Bold \\
\hline Formatted: Font: 8 pt, Not Bold
\end{tabular}

Formatted: Font: Times New Roman, 10 pt, Bold, Font color: Black

Formatted: Font: Times New Roman, 10 pt, Bold, Font color: Black

Formatted: Space After: $0 \mathrm{pt}$

Formatted: Font color: Black

Formatted: Font: $10 \mathrm{pt}$, Bold, Font color: Black

Formatted: Font: Times New Roman, 10 pt, Bold, Font color: Black

Formatted: Tab stops: Not at 82.5 $\mathrm{mm}+165.1 \mathrm{~mm}$
A MICROSIMULATION APPROACH TO EVALUATE OPERATIONS OF WEAVING SECTIONS AT URBAN UNCONV] INTERSECTIONS IN CAIRO

Soliman, A.K. and Abo Hashema, M.A.Soliman, A.K. and Abo Hashema, M.A.
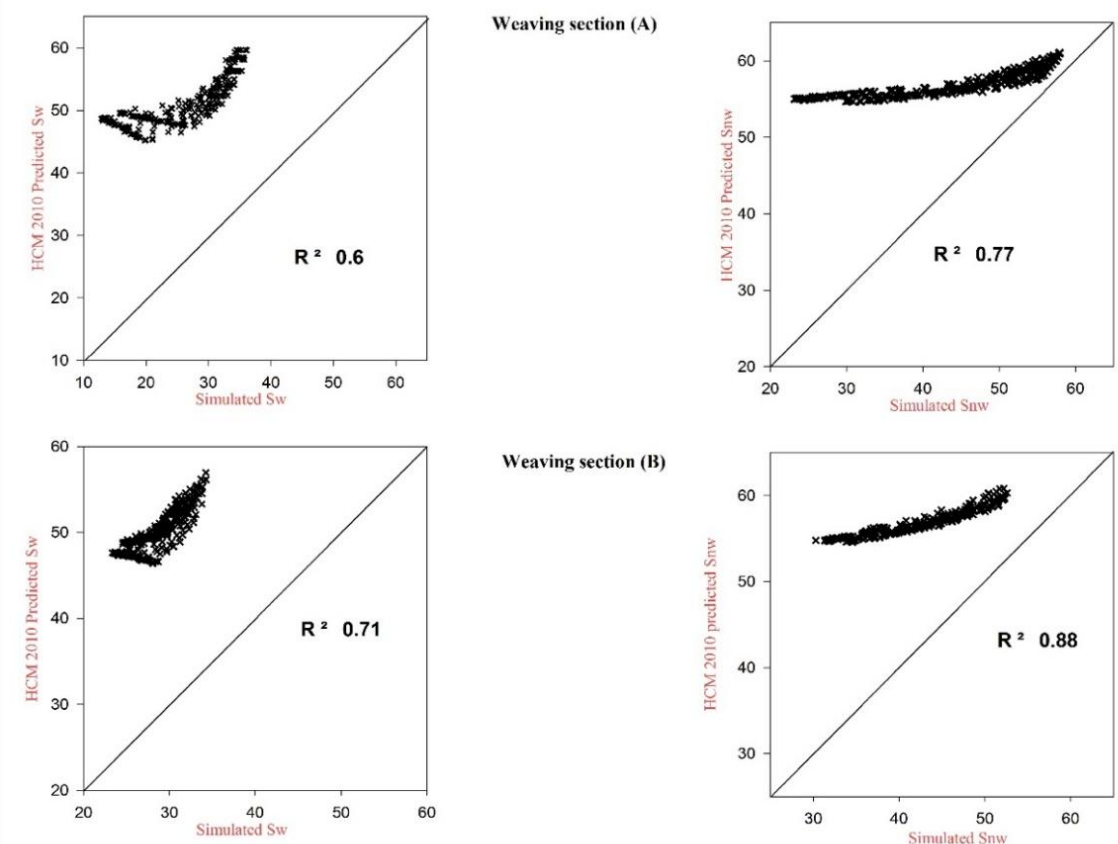

Weaving section (B)

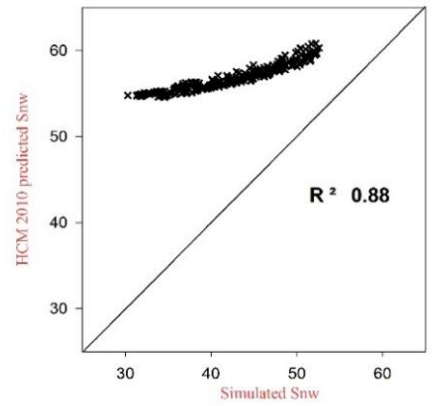

a. HCM 2010 Predicted speeds versus VISSIM simulated speeds for $\mathrm{WL}=100 \mathrm{~m}$

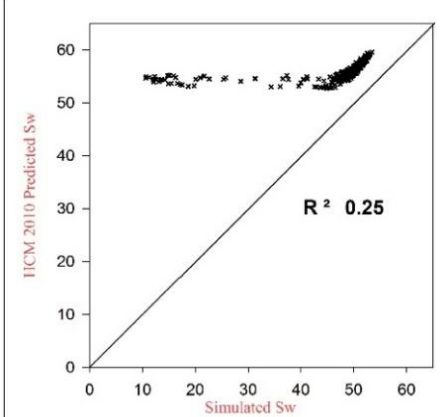

Weaving Section (A)
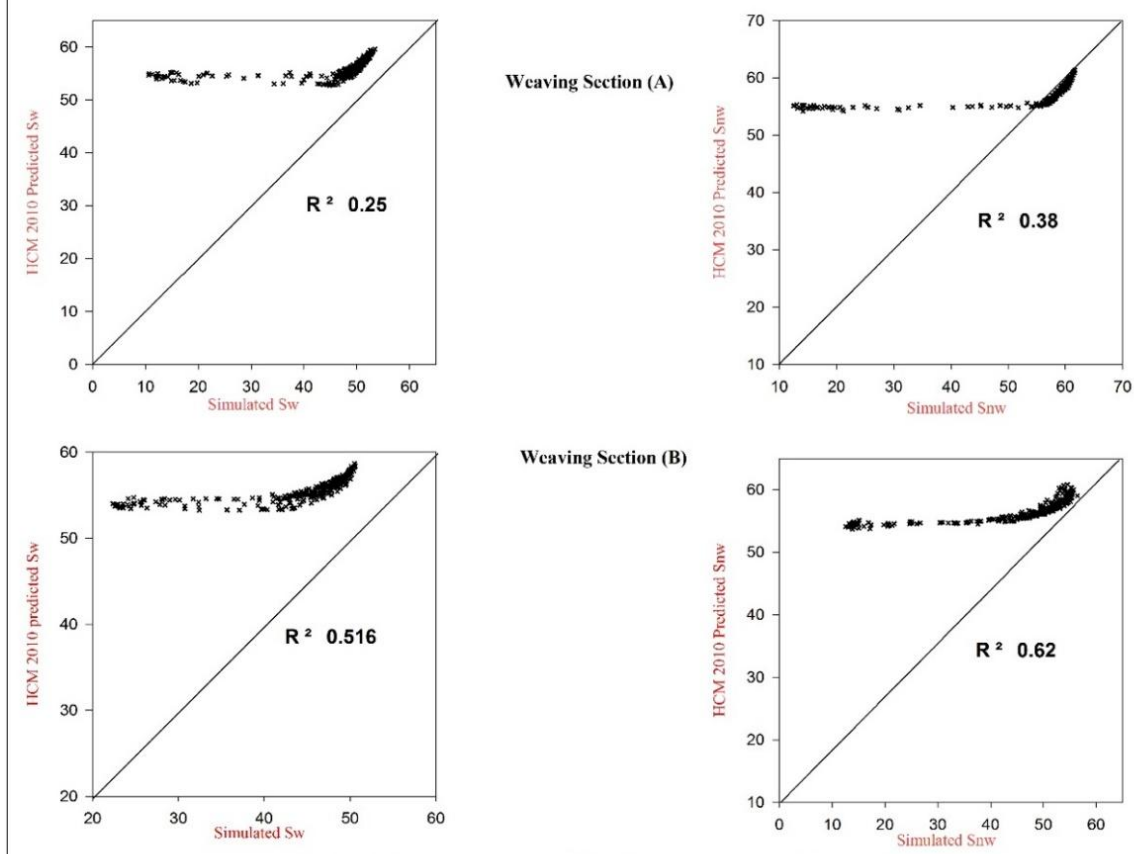

Weaving Scetion (B)

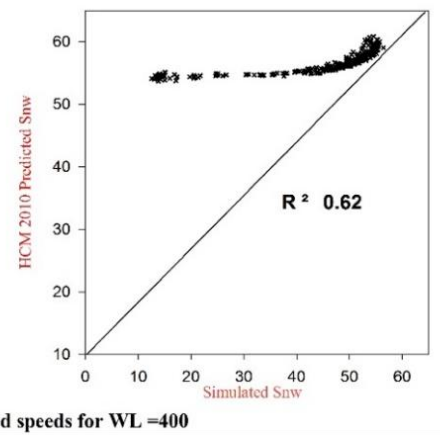

a. HCM 2010 Predicted speeds versus VISSIM simulated speeds for $\mathrm{WL}=400$

- Figure 12121314: Parity plots forof simulated the simulated verses the predicted weaving anc weaving Speeds 


\section{Formatted: Font: 8 pt, Not Bold \\ Formatted: Font: 8 pt, Not Bold}

Formatted: Space Before: 0 pt, After: 0 pt, Line spacing: Exactly $12 \mathrm{pt}$
A MICROSIMULATION APPROACH TO EVALUATE OPERATIONS OF WEAVING SECTIONS AT URBAN UNCONV] INTERSECTIONS IN CAIRO

Soliman, A.K. and Abo Hashema, M.A.Soliman, A.K. and Abo Hashema, M.A

\section{\$5.4-Calibrating the HCM speed prediction modelmodelss}

Using the non-linear regression procedure in SPSS, an effort was undertaken to calibrate an the HCM speed prediction algorithms with using the simulation data points to represe conditions more accuratelywith the hope of representing better urban conditions. The model original forms use a minimum speed of upper and lower $15 \mathrm{mph}$ and a maximum speed-spee to the free flow speed FFS(FFS).

-The minimum value observed ef from simulated-the simulation modelsspeeds for the urban sections was were lower than $15 \mathrm{mi} \mathrm{mph} / \mathrm{hr}$; thereforetherefore, the original models were mo using the actual observed minimum speed of $6 \mathrm{mph}-\mathrm{mi} / \mathrm{h}$. Also all lengths were used in units

Each weaving section was considered as a separate configuration. Free flow speed (FFS) valu $\mathrm{mi} / \mathrm{h}(60 \mathrm{~km} / \mathrm{h})$ was used for substituting the FSS-FFS in SPSSSPSS; therefore,therefore, $\mathrm{tl}$ format was used as following:

$$
S_{W}=6+(F F S+z a 6) /\left(1+\left(b *\left(L_{C A L L} / L_{S}\right)^{C}\right)\right.
$$

\section{Calibrated Weaving speed prediction model for Section (A)}

$S_{W}=6+\frac{F F S-6}{1+W} \quad$ where $\quad W w W=0.322437 *\left(\frac{\mathrm{LC}_{\mathrm{ALL}}}{\mathrm{L}_{\mathrm{S}}}\right)^{1.386716}$

The calibrated model resulted in $\mathrm{R}^{2}$ of 0.54 which 0.54 , which is not bad when compared to a 0.614 obtained by freeway basedfreeway-based data $[6]$.

-Calibrated Weaving speed prediction model for Section $(B)$

$S_{W}=6+\frac{F F S-6}{1+W} \quad$ where $\quad W w W=0.557494 *\left(\frac{\mathrm{LC}_{\mathrm{ALL}}}{\mathrm{L}_{\mathrm{S}}}\right)^{0.787467}$

The calibrated model resulted in an $\mathrm{R}^{2}$ of 0.343 -compared to the previous calibrated model.

Attempts to calibrate the non-weaving speed prediction model failed to produce any si results, which was quite expected given that, the non-weaving speed prediction model was $\epsilon$ a weak part of the HCM 2010 weaving analysis methodelogy methodology. 6 .

In view of the above, it is evident that the structure of the model gives a very low $R^{2}$ even $f f$ (A). On the other hand, efforts to calibrate the non weaving speed prediction model provided 2010 failed completely $\underline{t}$ Therefore, it is not recommended for any future Attempts.

In view of the above, it is evident that speed prediction is extremely difficult and rarely 1 statistically acceptable models.
Formatted: Tab stops: Not at 82.5 $\mathrm{mm}+165.1 \mathrm{~mm}$ 


\begin{tabular}{|l|}
\hline Formatted: Font: 8 pt, Not Bold \\
\hline Formatted: Font: 8 pt, Not Bold
\end{tabular}

Formatted: Space Before: 0 pt, After: 0 pt, Line spacing: Exactly $12 \mathrm{pt}$, No bullets or numbering
A MICROSIMULATION APPROACH TO EVALUATE OPERATIONS OF WEAVING SECTIONS AT URBAN UNCONV] INTERSECTIONS IN CAIRO

\section{Soliman, A.K. and Abo Hashema, M.A.Soliman, A.K. and Abo Hashema, M.A.} 4

$\rightarrow 18$.

19.

20 .

21 .

22.

23.

24 .

25 .

26.

27.

\section{CONCLUSION}

This paper presented an effort to model and simulate urban weaving sections resulting unconventional intersection design adopted widely in Cairo, Egypt. Due to this design type lack of traffic control, merging of minor traffic into the mainstream and its ability to crossgreatly affected by major approach demand. Higher major approach volumes produces lesser the minor merging traffic, therefore lesser minor approach throughput and capacity. Each major demand was associated with a maximum throughput that can propagate through the ramp i.e. capacity of the entrance ramp.

It was found that at some point, continuous increase in weaving length does not necessarily traffic operations and could reduce the capacity and LOS. It was also concluded that 200 met optimum length for maximum capacity and throughput of the weaving sections and tl entrance. However, it is recommended to try to experiment lengths between 200 and $300 \mathrm{n}$ future work. It is worth mentioning that Michigan department of transportation (MDOT) reet a weaving length of $200 \pm 30 \mathrm{~m}$ as the optimum weaving Length for efficient operations whir with the findings of this research.

Form the comparative analysis with HCM 2010 methodology, it was concluded that, methodology for these types of urban weaving configurations willwould produce unreliabl HCM 2010 models are more likely to predict lower lane changing rates, overestimated capar higher speeds. This is probably attributed to the fact that the prediction models of the HCM 2 designed for freeway eenditions whichconditions, which naturally involves lower rates of lower lane changes, higher speeds and higher capacities compared to urban conditions. It was also concluded that the HCM capacity model structure fails to compensate the capac: due to the increase in weaving ratio when length increases.

Efforts to calibrate the speed prediction algorithms revealed that the original structure of the 1 not suited to represent weaving operation even when fitted and calibrated with the simula points. It was also concluded that speed prediction of weaving operations is extremely ne difficult, and rarely results-producesin "statistically acceptable" results.

Utilizing this intersection design at areas with high crossing demand volumes are likely to ca back into the minor approach and enhances the chances of forming a bottleneck at the conf between the arterial and the crossing.

-At high crossing demands, mainstream vehicles penetrates through the section with very lo and could be forced to queue with the U-turning vehicles until sufficient gap arises. Ther efficient weaving operations the design should be implemented at areas with low crossing conditions and cannot be used at major intersections.

This study assumed similar volume condition at both intersection of the simulated Intersection with different volume conditions will results in a more complex weaving opere more complex weaving operation with 4 weaving section interacting with each other. This ci for future work.
Formatted: Tab stops: Not at 82.5 $\mathrm{mm}+165.1 \mathrm{~mm}$ 


Formatted: Font: 8 pt, Not Bold
Formatted: Font: $8 \mathrm{pt}$, Not Bold
Formatted: Space After: $0 \mathrm{pt}$

A MICROSIMULATION APPROACH TO EVALUATE OPERATIONS OF WEAVING SECTIONS AT URBAN UNCONV] INTERSECTIONS IN CAIRO

Soliman, A.K. and Abo Hashema, M.A.Soliman, A.K. and Abo Hashema, M.A. 1

\section{Formatted: Font: (Default) Calibri}

Formatted: Space After: 0 pt, Line spacing: Exactly $12 \mathrm{pt}$

Formatted: Font: $11 \mathrm{pt}$, Font color: Auto, Complex Script Font: 11 pt

Formatted: Space After: $0 \mathrm{pt}$

Formatted: Font: 11 pt, Not Bold, Font color: Auto, Complex Script Font: $11 \mathrm{pt}$
Formatted: Tab stops: Not at 82.5 $\mathrm{mm}+165.1 \mathrm{~mm}$

\section{REFERENCES}

$\rightarrow$ 1. Manual, H. C. (2010). Transportation Research Board of the National Academies, 2010.

$\rightarrow 2$. Manual, H. C. (1950). Practical Applications of Research. Bureau of Public Rc Department of Commerce, Washington DC.

3. Normann, O. K. (1957). Operation of Weaving Areas. Highway Research Board Bulletin

4. Manual, H. C. (1985). Special report 209. Transportation Research Board, Washingtor 985

5. Manual, H. C. (2000). HCM 2000. Washington, DC: Transportation Research Board.

6. Roess, R., and J. Uliero. "Analysis of Freeway Weaving Sections." Final Report, NCHR (2008): 3-75.

7. Fazio, J. (1985). Development and Testing of a Weaving Operational Design and Procedure. Master's thesis, University of Illinois at Chicago, Chicago IL.

8. Zarean, M., \& Nemeth, Z. A. (1988). WEAVSIM: A microscopic simulation model of weaving sections (No. 1194).

9. Wicks, D. A., \& Lieberman, E. B. (1976). Development and testing of INTRAS, a mic freeway simulation model. Volume I. Program design and parameter calibration (No. FH 76-75 Final Rpt.).

10. Skabardonis, A., Cassidy, M., May, A. D., \& Cohen, S. (1989). Application of simu evaluate the operation of major freeway weaving sections (No. 1225).

11. Fazio, J., \& Rouphail, N. M. (1990). Conflict simulation in INTRAS: Application to wea capacity analysis. Transportation Research Record, (1287).

12. Halati, A., Torres, J., \& Mikhalkin, B. (1990). Freeway simulation model enhancer integration-FRESIM technical report. Federal Highway Administration, Report No. I 85-C-00094.

13. Rathi, A. K., \& Santiago, A. J. (1990). Urban Network Traffic Simulations: TRAFProgram. Journal of transportation engineering, 116(6), 734-743.

14. Nowlin, R. L., \& Fitzpatrick, K. (1998). ANALYSIS OF TWO-SIDED W] OPERATIONS. In 68th Annual Meeting of the Institute of Transportation Engineers

15. Van Aerde, M. (1992). INTEGRATION, a Model for Simulating Integrated Traffic N User's Guide for Model Version 1.4 D.

16. Stewart, J., Baker, M., \& Van Aerde, M. (1996). Evaluating weaving section desig INTEGRATION. Transportation research record: Journal of the transportation researc (1555), 33-41.

17. Zhang, Y., \& Rakha, H. (2010). Systematic analysis of capacity of weaving sections. Sayed, Alnuaimi \& Masad (eds.), Efficient Transportation and Pavement Systems, 151-11

18. PTV, A. (2011). VISSIM 5.40 User Manual. Karlsruhe, Germany.

19. Wiedemann, R. (1974). SIMULATION DES STRASSENVERKEHRSFLUSSES

20. Vu, T. T., Roess, R. P., Ulerio, J. M., \& Prassas, E. S. (2007). Simulation of a weaving st Transportation Research Board 86th Annual Meeting (No. 07-0111).

21. Pesti, G., Chu, C. L., Fitzpatrick, K., Porter, R. J., \& Le, T. Q. (2011). Simulation of Traffic Between Freeway Ramps. In Transportation Research Board 90th Annual Mee 11-3084). 
Formatted: Font: 8 pt, Not Bold

Formatted: Font: 8 pt, Not Bold

Formatted: Space After: 0 pt, Line spacing: Exactly $12 \mathrm{pt}$
A MICROSIMULATION APPROACH TO EVALUATE OPERATIONS OF WEAVING SECTIONS AT URBAN UNCONV] INTERSECTIONS IN CAIRO

Soliman, A.K. and Abo Hashema, M.A.Soliman, A.K. and Abo Hashema, M.A.

4

22. Liu, X., Wang, Y., Schroeder, B., \& Rouphail, N. (2012). Quantifying Cross-Weave I Capacity Reduction for Freeway Facilities with Managed Lanes. Transportation Research Journal of the Transportation Research Board, (2278), 171-179. 